\title{
Use or Not Use? The Role of Trust and Habit in mHealth Ser-vices Use Intention Among Older Population in Hong Kong
}

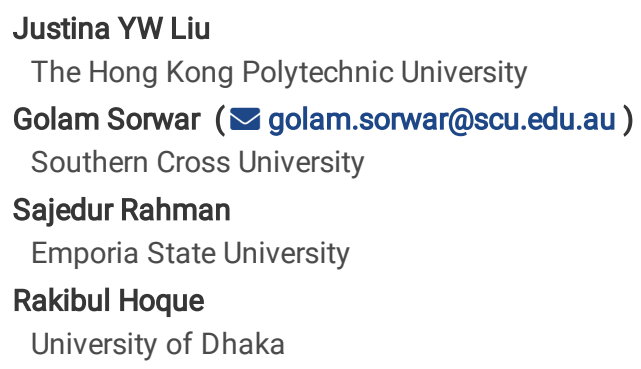

Research Article

Keywords: UTAUT2, Elderly, health technology service acceptance

Posted Date: February 15th, 2022

DOI: https://doi.org/10.21203/rs.3.rs-1271844/v1

License: () (1) This work is licensed under a Creative Commons Attribution 4.0 International License. Read Full License 


\section{Abstract}

Background: Evidence from literature suggests that mobile health (mHealth) services can potentially improve healthcare outcomes among elderly population. Hence, the government of Hong Kong has recently taken several community and IT services initiatives for training older people on how to enhance their abilities and interest in using mHealth technology. Although mHealth services have been widely implemented worldwide, their adoption and use by elderlies are very low including those in Hong Kong. This study aims to understand key factors influencing mHealth use intention among the elderly Chinese population in Hong Kong.

Methods: We extended the Unified Theory of Acceptance and Use of Technology (UTAUT2) as the basis of our conceptual framework. We applied Partial Least Squares path modeling method to conduct the Structural Equation Model (SEM) technique that allows measuring the theoretical validity of any conceptual framework. A convenience and snowball sampling methods were used to recruit community-dwelling older people aged 65 or above. In total, 201 valid responses were used for testing the theoretical validity of the proposed conceptual framework.

Results: The primary finding shows that the widely used UTAUT2 model falls short in explaining mHealth service acceptance behavior in the elderly population. We further propose a simplified model, the Healthcare Technology Service Acceptance (HTSA) model, to understand the formation of mHealth service acceptance behavior. The findings show that trust is an important component of technology service acceptance intention behavior that was missing in the UTAUT2 model. The results also show that several antecedent factors (i.e., social influence, government policy, and service quality) are critical in forming technology trust beliefs.

Conclusions: The study shows that the HTSA model can better explain mHealth acceptance behavior than the UTAUT2 model. This study advances knowledge in the mHealth technology adoption domain by proposing a simplified new version of the UTAUT2 model for understanding healthcare technology service acceptance and use intention among the elderly population. The findings of the study provide valuable information to the Hong Kong government and healthcare organizations for a wider adoption of mHealth services specially in older populations. "

\section{Introduction}

In recent decades, we are experiencing a demographic shift in the world due to increased life expectancy and a sharp decline in birth rates. Although these are clearly major achievements of modern sciences and improved healthcare, a new set of challenges have emerged in recent years regarding the independent living of elderlies. Governments are also working to address the challenges of an aging population (1). The number of elderly people per 100 working-age population is expected to triple by 2060 (2). Thus, ensuring adequate care with adequate quality for community-dwelling elderly population and managing their health, therefore, pose a challenge for many governments in current situation as well as in future decades.

Technology such as mobile health has the potential to provide solutions for various health problems suffered by community-dwelling elderly adults (3-5). Rapid advances of mobile and telecommunication technologies worldwide have brought new opportunities, especially in the delivery of healthcare services to remote, elderly, and mobile-impaired population. Mobile health, commonly known as mHealth technology, refers to medical and public health services supported by mobile communications and network technologies (6). Reviews of mHealth technology research show that it is a useful platform for promoting healthcare for community-dwelling elderly people (7). The mHealth technology allows convenient and ubiquitous access to health services and health-related information at an affordable low cost (8). In addition to the low-cost healthcare services, there is growing evidence that mHealth services facilitates improved overall health and wellbeing of older people (9-12). Its application has increased recently following the COVID-19 pandemic, in which elderly population is the most impacted among all others (13)

Given the potential benefits of mHealth services, there is a growing popularity of this technology both in the developed and developing countries. Governments across the globe are showing their interest to take advantage of this modern technology. For example, considering the fact that mHealth literacy affects mHealth service adoption (14) the government of Hong Kong has recently taken several community and IT services initiatives to provide funding for training older people on how to enhance their abilities and interest in using mHealth technology, which has helped them to appreciate how digital technologies can enhance their quality of life (15).

Although various mHealth technologies (i.e. healthcare robots, telecare application, etc.) have been developed to support aging population in place, existing literature suggests that there has been only low-level of acceptance of these kinds of technologies among this population group (16,

17) (18). A plethora of research can be found investigating various factors contributing to the low acceptance. Our review of extant literature reveals a large body of literature that is focused on understanding the underlying mechanism and interplay of various factors influencing the use of $\mathrm{mHealth}$ technology by elderly population across different geographical regions. A closer look at healthcare technology adoption literature reveals a wide range of factors contributing to the low acceptance. They can broadly be grouped into few categories including - user knowledge and support, personal attributes, social factors, and usability factors. For example, fear of technology, technophobia among older people, dependence on family support for technology adoption and usage, and associated cost of using these platforms (19) prevent elderly people from utilizing services using mobile technologies.

Technology adoption literature also suggests that self-actualization plays an important role in new technology adoption and usage, and elderly people usually need to have a higher level of self-actualization than people who are middle-aged (20). Others have reported personal attributes, such 
as self-efficacy, anxiety, social influence, training, and encouragement have influence on healthcare technology usage among elderly population (21, 22). A large group of researchers have reported usability factors, such as usefulness, ease of use, compatibility, intuitiveness of graphical user interfaces, performance expectancy, effort expectancy, and resistance to change (23-26) are some of the major factors that contribute to the likelihood of mHealth technology usage by elderly population. Moreover, aging has been found to be negatively related to the perceived ease of use and perceived usefulness of technology, two significant predictors of technology acceptance, which could represent a barrier to the adoption of mHealth by older people (25).

In addition to the various factors mentioned above, some studies suggest that national and government health policies may have important influence on users' perceptions of the health system and their actual use. For example, better management, organization, and effective use of resources through national health policies can strengthen the health system and enhance the quality of healthcare delivery (27). Study also shows that government funding, plans and policies have a significant impact on wider adoption of mhealth services, leading to quantitative advances (28, 29). Hence, governments need to play an active role in supply-side factors to facilitate the delivery of large-scale information communication technology (ICT)-mediated health benefits for their citizens, including disadvantaged people (30). On the other hand, trust have shown significant influence on the intention to use mHealth by elderlies(13, 31-33).

More attention is needed to explain the factors that influence the technology adoption by elderlies, particularly because of having different findings in different studies in different contexts for elderlies. Researchers often extend the existing technology acceptance models such as UTAUT2 model to explain mHealth acceptance behavior. However, despite many studies, there is still a lack of empirical studies testing the influence of government health policies on health technology, especially mHealth acceptance and usage. Typically, when explaining mHealth acceptance behavior, the UTAUT2 model does not consider the influence of government health policies and trust and its antecedents. Hence, the authors argue that developing a new model and comparing its ability in explaining mHealth acceptance behavior with regard to UTAUT2 model is necessary.

Therefore, with an objective to develop a new technology acceptance model, the authors used the extended unified theory of acceptance and use of technology (UTAUT2) theory as a fundamental basis for understanding the factors that affect the healthcare technology use behavior. The objective of this study was twofold. First, we attempted to check the adequacy of UTAUT2 model in explaining mHealth technology adoption among elderly population. Second, in efforts to better understand factors that are behind the process of healthcare technology services acceptance, we proposed and tested a simplified health technology service acceptance (HTSA) model. Using empirical analyses, we show that the proposed HTSA model is more appropriate for healthcare context and have better explanatory power for understanding healthcare technology adoption behavior where UTAUT2 falls short in understanding such behavior among elderly population.

When experimenting, we first applied the original UTAUT2 model in the context of mHealth adoption by the elderly Hong Kong population. We then extended the UTAUT2 model by including three additional constructs (Government Health Policy, Service Quality, and Trust). After analyzing the results from the first two models, we, finally, proposed a simplified model that we believe has better explanatory power of mHealth services adoption intention by the elderly population in Hong Kong. Given the ongoing pandemic that is mostly risking the lives of older population, it is critical that we focus on the utilization of technology to address healthcare challenges for this population group. We believe that this study is very timely and provides important insights in understanding healthcare technology acceptance behavior by elderly population, contributing in both research and practice.

\section{Literature Review, Theoretical Models And Hypotheses}

\section{mHealth}

In 2011, World Health Organization (WHO) defined mobile health (mHealth) as the: "medical and public health practice supported by mobile devices, such as mobile phones, patient monitoring devices, personal digital assistants (PDAs), and other wireless devices" (34). mHealth technology has enormous potential for assisting elderlies in self-management of health, chronic disease management, and living healthy such as assistance for persons with dementia through mobile-app (35). mHealth encompasses receiving healthcare services in various ways, such as voice and short messaging service (SMS), mobile apps, third and fourth generation mobile telecommunications, and mobile sensors integrated with the internet of things (loT). Today, mhealth services for various age groups, including elderlies(36-39) are emerging as a new field in the healthcare industry and research(18).

\section{Theoretical models}

The process of technology acceptance by users has been studied for many years and various theoretical models on technology acceptance have been developed over time. While some theories, such as technology acceptance model (TAM) and theory of reasoned action (TRA), laid the foundation for understanding users' technology acceptance behavior, other theories, such as unified theory of acceptance and use of technology (UTAUT) and UTAUT2, advanced our understanding of this process. Although TAM and TRA provided much needed insights into the major universal factors that are likely to affect a user's perceptions of a particular form of technology, UTAUT2 is recognized by researchers (see for example: 40,41 46) as one of the leading theoretical models with its strong empirical support for the acceptance of various forms of technology by end-users. Given 
the widespread and global acceptance of UTAUT2, this study is grounded by this theoretical model. We believe that the UTAUT2 model provides us with necessary foundation for this study and allows us to drive a more simplified model that is more appropriate in the context of our study.

The original UTAUT (47) theory was incepted in 2003 to explain users' intention to adopt new technology and their subsequent use behavior. It was developed by integrating the previous eight competing but dominant theories on technology adoption and its use. UTAUT was designed to provide a more unified view of understanding factors affecting new technology acceptance. According to UTAUT, the core constructs that influence individuals' intention to use technology are performance expectancy, effort expectancy, and social influence (47). UTAUT also asserts that facilitating conditions are important in forming individuals' actual use behavior, which together with intention can explain the actual technology use behavior (47). This unified view was later extended to UTAUT2 by including three additional factors - hedonic motivation, price value, and habit. These additional constructs are shown to provide insights for enhanced understanding of both behavioral intention and the actual use technology use behavior.

Since its inception, UTAUT-based research has thrived and made significant impact in both research and practice in the past decade. A review of extant literature suggests the utilization of UTAUT theory in a wide area of research including education settings $(44,45)$, eHealth literacy $(48)$, healthcare settings (49-51), and many other areas of technology use. Despite the wide use of UTAUT in Information Systems (IS) research, there are several limitations with UTAUT in explaining individuals' technology adoption behavior regardless of technological and demographical contexts. For example, UTAUT model does not consider cultural factors even though some studies suggest a significant role of culture on technology adoption (52). In addition, UTAUT theory also does not take into consideration the aspect of trust in determining behavioral intention and technology use behavior formation. Noting some of these limitations with the utilization of UTAUT, Venkatesh et al. (53) called for a paradigm shift of UTAUT extensions in technology acceptance and use. The authors of UTAUT further recommended the use of this model using the theoretical notion of contextualization because "context has become one of the important theoretical lens" in IS research (53). Thus, in this study, we grounded our foundation using UTAUT2 as shown in Figure 1 and contextualized the theory in the context of mHealth services use by the elderly population in Hong Kong.

H1: Performance expectancy is positively associated with an individual's behavioral intention to use mHealth services.

H2: Effort expectancy is positively associated with an individual's behavioral intention to use mHealth services.

H3a: Social influence is positively associated with an individual's behavioral intention to use mHealth services.

H4: Facilitating conditions is not important in determining behavioral intention to use mHealth services.

H5: Habit is positively associated with an individual's behavioral intention to use mHealth services.

H6a: Hedonic motivation is positively associated with an individual's behavioral intention to use mHealth services.

H7a: Price value is positively associated with an individual's intention for the use of mHealth services.

\section{Performance Expectancy}

Performance Expectancy refers to "the degree to which an individual believes that using the system will help him or her to attain gains in performance" (47). In the context of this study, we define PE as the degree to which an individual believes that using mHealth services will enhance the condition of his or her health. PE has been found as one of the strongest predictors (see for example: $51,54,55$ ) of individuals' behavioral intention (BI) to adopt and use technology. PE is also found as a powerful determinant in the intention to adopt new healthcare related technologies. For instance, the study by Hoque and Sorwar (24) on the adoption of mHealth in the context of Bangladesh reported that PE has a direct effect on behavioral intention. Their study indicated that one unit of change in performance expectancy could cause more than 0.31 units of change in behavioral intention. Similarly, Woldeyohannes and Ngwenyama (56) studied the influence of PE on BI for mHealth adoption and reported PE is very relevant for $\mathrm{mHealth}$ adoption considering the ability to meet time-demand with accurate content and reliable performance. Apart from general users, when studied on health professionals such as physicians, PE also affected BI significantly (57). Therefore, based on the evidence found in existing literature, we proposed the following hypothesis.

H1: Performance expectancy is positively associated with an individual's behavioral intention to use mHealth services.

\section{Effort Expectancy}

Venkatesh et al. (47) defined effort expectancy (EE) as "the degree of ease associated with the use of the system". We define EE in the context of this study as the degree to which an individual believes that receiving mHealth services are easy without needing significant efforts. EE has been reported to have a significant positive impact on technology use behavioral intention (see for example: 44, 51, 54). Researchers also identified this construct as a key factor that directly influences users' intention in using healthcare systems. For example, Sun et al. (58) reported a significant relationship between these two constructs when studied for mobile health monitoring systems. A significant predictor of BI was found in the study by Woldeyohannes and Ngwenyama (56) when the users were asked about the level of difficulty they might find in using mHealth. Hoque and Sorwar (24) also found EE as a determinant of intention in the Bangladesh context. Moreover, Breil (59) studied the acceptance of mHealth

Page $4 / 28$ 
applications among people with hypertension and EE to be a significant predictor of BI. Based on these findings, we proposed the following hypothesis:

H2: Effort expectancy is positively associated with an individual's behavioral intention to use mHealth services.

\section{Social Influence}

Venkatesh et al. (47) defined social influence (SI) as "the degree to which an individual perceives that important others (e.g., family and friends) believe they should use the new system." In this study, we define SI as the degree to which an individual believes that his or her decision to receive mHealth services is influenced by significant others. Existing research (see for example: 60,61 ) suggest SI a significant contributor to individuals' behavioral intention decision when pertaining to technology use. In the healthcare context, SI has a strong impact on users' intention to adopt new technology. For example, it is widely found significant in the developing countries where the family members generally influence the elderly users to use mHealth (see for example: 24,62). Similarly, Kijsanayotin et al. (51) reported that SI positively influences individuals' health information technology adoption intention in Thailand's community health centers. Furthermore, Sun et al. (58) found significant positive influence of SI on individuals' adoption intention of mobile health services. Thus, relying on the findings in existing literature, we posited the following hypothesis for the relationship between an individual's social influence and his or her behavioral intention to use mHealth services.

H3a: Social influence is positively associated with an individual's behavioral intention to use mHealth services.

H3b: Social influence positively influences an individual's trust belief in mHealth services.

\section{Facilitating Conditions}

Facilitating condition (FC) describes users' perceptions about potential (situational or environmental) conditions that either facilitate or hinder for taking certain action(s). The potential conditions can be influenced by either internal or external or both factors. In the original UTAUT study, Venkatesh et al. (47) refer to it as "the degree to which an individual believes that an organizational and technical infrastructure exists to support the use of the system". To fit the context of this study, we defined FC as the degree to which an individual believes they have the necessary knowledge, resources, and supports for using mHealth services. As we study this technology use by older population, we believe FC will play a critical role and a dominating determinant of $\mathrm{Bl}$, given that this group of population is specifically known to lack behind and inexperience in using different technologies (see for example: 63). FC has been found to be a determinant in BI for using different technologies. Venkatesh et al. (47) have shown the importance of facilitating condition in shaping individuals' behavioral intention. This construct is also found to influence healthcare technology use behavior. For example, Dwivedi et al. (64) conducted a cross-country study on adopting mHealth services in the context of USA, Canada, and Bangladesh, and reported facilitating condition significantly influence behavioral intention to utilize the technology. Cimperman et al. (26) also reported a similar finding in investigating the elderlies' acceptance behavior regarding telehealth services. However, Venkatesh et al. (47) stated that the influence of facilitating conditions on behavioral intention diminishes and it is non-significant in predicting intention if both performance expectancy and effort expectancy are presence in the model. Several other studies $(24,55,65)$ also found non-significant relationships between these two constructs in the presence of performance expectancy and effort expectancy constructs. Thus, based on the evidence in the existing literature, we proposed the following hypothesis regarding the relationship between facilitating condition and behavioral intention to use of mHealth services.

H4: Facilitating conditions is not important in determining behavioral intention to use mHealth services.

\section{Habit}

Since the incorporation of habit (HA) in the extended UTAUT model, a growing number of studies are focused on understanding the impact of habit on technology adoption decision. Habit can be defined as individuals' unconscious and automatic past behavior that is frequently repeated.

Researchers have attributed habit for overriding intentional action (66). Venkatesh et al. (54) described habit as "the extent to which people tend to perform behaviors automatically because of learning". Habitual behavior is known as a repetition of past behavior in the future given all other conditions being equal (67). In the context of this study, we define habit as an individual's belief about his or her frequent use of mHealth services and one's natural reliance of this technology for healthcare needs. Existing research (see for example: $47,68,69$ ) suggests that consumers' habits play a significant impact on technology use, both directly and as a behavioral intention path to affect their behavior. In fact, "the learning process at the early stages of IS adoption will be complemented once users gain the necessary knowledge about the goals of using the IS" (70). Evidence in existing literature suggests a significant positive and direct relationship between consumers' habits and their behavioral intentions to use technology (see for example: 67, 71). In fact, some reported habit is more significant for elderly population for forming their technology related behavioral intention (72). Furthermore, several recent studies (see for example: 43,70 ) linked habit with individuals' behavioral intention to adopt healthcare-related technologies. As it can be safely assumed that "habitual previous behavior in a given context will predict behavioral intentions in the same context" (67), we believe individuals' habit of using technology for personal needs will influence their behavioral intention to use mHealth services for similar needs. Hence, the following hypothesis was proposed.

H5: Habit is positively associated with an individual's behavioral intention to use mHealth services.

Page 5/28 


\section{Hedonic Motivation}

Venkatesh et al. (54) defined hedonic motivation (HM) as "the fun or pleasure derived from using technology". Research has shown strong relationship between this construct and behavioral intention to acceptance and use of technology. For example, Brown and Venkatesh (73) reported hedonic motivation to play an important role in determining technology acceptance. Alalwan et al. (74) found HM to have significant positive influence on consumers' intention to adopt Internet banking. To understand the impact of user acceptance of mobile technology in healthcare, Sudbury et al. (75) reported that HM has significant impacts on BI in the healthcare context. Gao et al. (76) found that hedonic motivation significantly influences individuals' behavioral intention to accept wearable technology for healthcare purposes. In a recent study, Talukder et al. (65) also validated the efficacy of the UTAUT2 for healthcare technology adoption context and found HM significantly influences individuals' behavioral intention to accept wearable healthcare technology by elderly population. Therefore, relying on the evidence from existing literature, we posited the following hypothesis regarding the relationship between hedonic motivation and behavioral intention to use mHealth services by elderly population.

H6a: Hedonic motivation is positively associated with an individual's behavioral intention to use mHealth services.

Hedonic motivation is also known to influence people's habits. Although most technology adoption studies suggest strong relationship between hedonic motivation and intention to use technology, a few studies investigated interrelationship between hedonic motivation and habit. Habit is found as a mediator between hedonic motivation and intention to use technology (77) such that hedonic motivation influences people habit, which in turn influence behavioral intention. Furthermore, Chiu (78) found that hedonic motivation leads to the building of Habit of technology use. Based on this evidence in existing literature we believe that hedonic motivation is an important antecedent of people's formation of habit and, thus, posited the following hypothesis.

H6b: Hedonic motivation is positively associated with Habit in the use of mHealth services.

\section{Price Value}

Price value (PV) is an outcome of a cost-benefit decision as individuals go through a process of cost and benefit analysis to gauge their perception about the value of certain products or services. The tradeoff between consumers' benefits (i.e., efficiency, convenience, quality, etc.) and costs (i.e., monetary expenses, difficulty of use, sacrifice, etc.) perceptions determine their value perceptions, which then further influences their decision. Thus, researchers defined perceived value as "consumers' cognitive tradeoff between the perceived benefits of the applications and the monetary cost for using them" (54). Aw et al. (79) referred to it as "consumers' perception toward subjective worthiness of service consumption". In the context of this study, we define perceived value as the degree to which an individual believes that the use of mHealth services will provide more benefits than the costs of using the technology. A number of studies have shown that users' perception of value derives from people's intention to use and continue to use technologies and technological services. For example, Mehta et al. (80) reported a direct and positive influence of price value in individuals' behavioral intention to adopt e-learning technology. Aw et al. (79) also reported a positive relationship between perceived value construct and consumers' intention to use ridesharing services. Many other studies $(54,81)$ have also suggested a similar relationship between these two constructs. As mHealth is a cost-effective medium of receiving healthcare service, the researchers infer that it is a strong determinant of behavioral intention to continue to use the technology $(68,82,83)$. Thus, the following hypothesis was posited.

H7a: Price value is positively associated with an individual's intention for the use of mHealth services.

Although there is no study to date shows a direct relationship between price value and habit, studies on the formation of people habit suggest that people habit can be influenced by increasing or decreasing value or reward. For example, Loewenstein et al. (84) reported that increasing incentives help in forming habits with regards to healthy food consumption. Thus, we hypothesized the following relationship between price value and habit.

H7b: Price value is positively associated with an individual's habit in using mHealth services.

\section{Trust}

As technology is integrated into every aspect in our lives, technology trust is considered one of the most important facilitators of people's willingness to use technologies (85) and, thus, received attention by researchers and practitioners across different disciplines. Technology trust is defined as "the belief that specific technology has the capability, functions, or features to do for one what one needs to be done" (86). In the context of this study, we define technology trust (TR) belief as the degree to which an individual believes that mHealth technology has the capability to provide adequate and responsive help to fulfill their healthcare needs. Although UTAUT2 has been widely used to explain different technology adoption behaviors including healthcare technology adoptions, one of the criticisms for UTAUT2 is that it lacks a trust component. Technology adoption decisions are often facilitated by individuals' trust on the specific technology. For example, a number of studies (87-89) can be found reporting trust on Internet technology is an essential facilitator in people engaging in online transactions. Thus, it is important that we explore the relationship between trust and behavioral intention in studying mHealth technology adoption.

The influence of technology trust in technology adoption decision is well cited in existing IS literature. Many studies (see for example: $90,91,92)$ can be found focusing on understanding the trust belief and its influence on technology adoption decision. Lankton et al. (93) studied the differences 
between human-like trust and system-like trust and found that individuals' trust related to specific system is an important antecedent for intention to continue to use the system. Technological trust is even more important in healthcare as more and more healthcare services are being delivered using technology that requires patients' interaction, engagement, and disclosure of their sensitive health and personal information. Lack of trust in healthcare technology can result to many adverse effects on patients' health. Studies suggest that lack of trust on healthcare technology leads to non-disclosure of necessary health information (94-96), which are critical in providing appropriate lifesaving care for patients. Zulman et al. (97) studied technology trust and use of healthcare resources by elderly population and reported distrust on Internet technology is responsible for the avoidance to use the technology as a health resource. Greater Trust is believed to affect behavioral intention positively. A very recent study by Alam et al. (82) also focuses on healthcare technology trust in a developing country. Their findings suggest that trust is appositively associated with behavioral intention to use healthcare technologies and one of the most significant predictors of mHealth apps adoption intention in Bangladesh. In a similar study, Meng et al. (98) also found that trust in mHealth services is essential for mHealth technology adoption by elderly users. Therefore, based on this evidence, we propose the following hypothesis for technology trust and behavioral intention to use mHealth services.

H8: Technology trust is positively associated with an individual's behavioral intention to use mHealth services.

As mHealth services are provided and received remotely, many factors can hinder or facilitate their successful delivery and reception. For example, the quality of service delivered is often time serve as factor that helps to gain trust which in turn determines continuous use of the technology. In addition, use of mHealth services requires clients to disclose and exchange their personal and sensitive data over the Internet using different devices, such as tables, cellphone, etc. The concern for security and privacy is an important factor in situations where data are exchanged between hosts and clients. Thus, given the complex nature of the trust construct, it is imperative that we dig deeper to understand how individuals' perceptions are formed for this construct. Thus, we include two additional constructs (Service Quality and Government Policy) that will serve as antecedent factors. We believe these two additional factors will provide important insights into the formation of mHealth services users' trust belief.

\section{Service Quality}

Although delivering quality service has been an essential component in the success of technology adoption, the construct, service quality (SQ), has found little attention in IS literature. The prevalent use of IT for improving customer satisfaction garnered much attraction on the topic of IT service quality in recent years. The perception of service quality is the consequence of individuals' evaluation of the quality of service received using technology. This concept emerged from marketing literature where customers are known to engage in assessing service they receive from vendors. Consumers' perception of service quality results from the comparison of customers' prior expectation and their perception of actual experience of service performance (99). This construct has been extensively studied in the marketing as well as consumer behavior literature, where service quality is commonly defined as individuals' judgement about overall superiority of service experience (100). In the context of this study, we define service quality perception as the degree to which mHealth services can meet the needs of its users. A number of research studies have found relationship between individuals' perceived service quality and their behavioral intention. Zeithaml et al. (101) studied the behavioral consequences of service quality on behavioral intention and reported important relationship between the two constructs. Similarly, DeLone and McLean (102) reported using their IS success model that service quality influences intention to use. Several other studies $(103,104)$ reported indirect relationships where service quality influences satisfaction, which in turn influences behavioral intention. Perceived serviced quality has also been studied in the healthcare context. For instance, Akter et al. (105) studied mHealth continuance intention in Bangladesh and found that service quality perception significantly influences the continuance of mHealth services use. Dagger et al. (106) conducted an in-depth study on service quality in the healthcare context and reported that perceived service quality has significant influence in individuals' intention to utilize healthcare services. Based on these evidences, we posited the following hypothesis.

H9a: Service quality perception positively influences an individual's behavioral intention to use mHealth services.

Individuals often rely on their experience with the quality of service they receive to gain a level of trust in the technology. Positive service quality experience increases their trust, whereas negative experience with service quality lowers their trust toward the technology. Evidence in existing literature also suggests a strong relationship between perceived service quality and individuals' trust beliefs. For example, a large number of studies (107-110) reported that service quality positively influences in shaping individuals' trust beliefs. In the context of healthcare, using an empirical study, Chang et al. (111) found service quality influences patient trust in medical services. Similarly, Akter et al. (105) studied mHealth services continuance use behavior and found that service quality not only influences behavioral intention but also influences trust beliefs, which in turn influences individuals mHealth services continuance intention. Thus, based on these findings, the following hypothesis is proposed.

H9b: Perceived service quality positively influences an individual's trust belief.

\section{Government Policy}

Government policy (GP) is known to shape the direction of citizens' product use. For example, if government of a country imposes sanction on using a certain type or brand of technology (e.g., US sanctions on using Huawei devices), it will prevent citizens from using that technology. On the other hand, if the government pass laws and regulations to promote certain product or services, citizens will find it easy to use them. Thus, government policies play a critical role in diffusing certain technology in society by making favorable policies and environments. In investigating technology 
adoption issues, Ejiaku (112) reported that various government policies play an important role in influencing citizens' technology adoption. Using SWOT analysis, Sharma and Sehrawat (113) concluded that environmental factors, such as lack of government policy, are responsible for adoption intention of cloud technology. In effort to study technology adoption in developing countries, Dasgupta et al. (114) found that environmental factor, such as government policies, have a significant impact on information technology adoption decisions. A recent study by Wang et al. (115) reports that government policy, such as use promotion, is one of the most important factors in users' continuance intention in using technology. Government policy is expected to enhance the acceptance of various healthcare technology, such as the use of electronic health record (EHR) and mHealth services. Acknowledging the importance and direct impact of government policy on technology adoption in healthcare, Middleton (116) and many other researchers have called for government policy change to facilitate technology adoption in the healthcare section. Llewellyn et al. (117) reported that healthcare policies act as a significant barrier or facilitator for promoting hospital and community-based services. Many studies recommended government policymakers to pass policies to increase mHealth adoption. For example, Hoque et al. (24) and Chen et al. (118) proposed to make government policies to maximize mHealth services adoption. Based on these evidences, we posited the following hypothesis for government policy and behavioral intention to continue to use mHealth services.

H10a: Favorable government policy positively influences an individual's behavioral intention to use mHealth services.

Government policy is also known to influence people's trust toward technology or service. Government policy often time shape whether individuals view certain technology or service as safe or risky. Especially if the technology requires people to disclose their sensitive personal information. In studying human resource information systems, Lippert \& Swiercz (119) suggest that policy is an important factor in establishing technology trust, and the level of trust among users guide their decisions whether to use or not to use the technology. The absence of an appropriate policy leads to uncertainties that motivate individuals to avoid technologies. Lu et al. (120) studied facilitating conditions of trust for wireless technology and found that policies play a key role in establishing users' trust, which in turn influences intention to use the technology. Although we found no study examining the relationship between government healthcare policies and healthcare technology trust and technology adoption, given the sensitive nature of health information, we believe healthcare policies promoted by government are a critical antecedent and have more impact on shaping users' healthcare technology trust beliefs. Thus, we posited the following hypothesis.

H10b: Favorable government policy is positively associated with an individual's trust belief.

In addition to the service quality and government policy, we believe social influence will also serve as an important antecedent factor for forming individuals' trust beliefs toward mHealth services. Existing research suggests that social influence greatly influences individuals' trust beliefs toward specific technologies. For example, Beldad et al. (121) argued that users are more inclined to trust a specific technology if they see widespread use and significant others expect them to use the technology. In studying the formation of trust in social network technologies, Chang et al. (122) found that social influence is a significant antecedent of technology trust and social influence positively influences individuals' trust beliefs toward the technology. Thus, we posited the following hypothesis.

H1: Performance expectancy is positively associated with an individual's behavioral intention to use mHealth services.

$\mathrm{H}$ 2: Effort expectancy is positively associated with an individual's behavioral intention to use mHealth services.

H3a: Social influence is positively associated with an individual's behavioral intention to use mHealth services.

H3b: Social influence positively influences an individual's trust belief in mHealth services.

H4: Facilitating conditions is not important in determining behavioral intention to use mHealth services.

H5: Habit is positively associated with an individual's behavioral intention to use mHealth services.

H6a: Hedonic motivation is positively associated with an individual's behavioral intention to use mHealth services.

H6b: Hedonic motivation is positively associated with Habit in the use of mHealth services.

H7a: Price value is positively associated with an individual's intention for the use of mHealth services.

H7b: Price value is positively associated with an individual's habit in using mHealth services.

H8: Technology trust is positively associated with an individual's behavioral intention to use mHealth services.

H9a: Service quality perception positively influences an individual's behavioral intention to use mHealth services.

H9b: Perceived service quality positively influences an individual's trust belief.

H10a: Favorable government policy positively influences an individual's behavioral intention to use mHealth services.

H10b: Favorable government policy is positively associated with an individual's trust belief. 
Figure 2 shown above is the extended UTAUT2 model that we propose as the second research model for this study. Based on the findings of our first two (UTAUT2 and Extended UTAUT2) research models, we propose the third simplified research model for this study. We refer to the simplified model as Health Technology Service Acceptance (HTSA) model, which is shown in Figure 3.

H3b: Social influence positively influences an individual's trust belief in mHealth services.

H5: Habit is positively associated with an individual's behavioral intention to use mHealth services.

H6b: Hedonic motivation is positively associated with Habit in the use of mHealth services.

H7b: Price value is positively associated with an individual's habit in using mHealth services.

H8: Technology trust is positively associated with an individual's behavioral intention to use mHealth services.

H9b: Perceived service quality positively influences an individual's trust belief.

H10b: Favorable government policy is positively associated with an individual's trust belief.

\section{Methodology}

\section{Instruments Development and Pretest}

The authors developed the items of measurement (see Appendix A) by conducting on extensive literature review. To ensure the validity of all measures, the measurement items for latent constructs within the proposed model were developed from prior studies. Items for PE, EE, SI, FC, HM, PV, and HA, were derived from Dwivedi et al. (64), Venkatesh et al. (47) and Venkatesh\& Davis (61). TR was derived from Fischer et al. (123). Items for SQ were derived from Akter et al. (105) and items for HP from Ejiaku (112) and Llewellyn et al. (117). A structured questionnaire was originally developed in English by the authors and then translated into Chinese by a professional translator. An expert panel, with an excellent command of the English language and good knowledge of mHealth, was then set up for the determination of the content validity index (CVI) of the translated Chinese questionnaire. Each question was rated on a 4-point Likert scale with 4 referred to most relevant. Any item in the Chinese questionnaire with a score below 3.5 was modified based on panel's recommendations until the score was above the desired mean score of 3.5. These modifications were done for a maximum of three times for only a few items. We also had a professor from language department to ensure the accuracy between English and Chinese versions. All items were rated using a five-point Likert scale, ranging from "strongly disagree" to "strongly agree".

\section{Data Collection Procedure}

A convenience and snowball sampling methods were used to recruit community-dwelling older people aged 65 or above and were able to read and communicate in Chinese. They had to be living in Hong Kong for at least seven years. Older people were excluded if they had cognitive impairment and / or physical impairment (such as blindness) that rendered them unable to use smartphones and mobile apps. Older adults with experience of using mobile apps were recruited.

Ethical approval for this study was obtained from The Human Subjects Ethics Committee of The Hong Kong Polytechnic University. Permission to conduct the study was also sought from the person in charges of the community center for older people. Flyers introducing the aims of this study were posted at the centers. Older people who wanted to join the survey were enrolled through the centers. The eligibility of those wanting to participate in this study was assessed by a well-trained research assistant (RA) according to sample selection criteria. Written informed consent was obtained from each participant before they took part in a structured face- to- face interview. All of the interviews were conducted by the RA according to a structured interview guideline developed by the principal investigator.

Participants could also complete the survey through an online platform - mySurvey. Those who were eligible and interested to participate completed an online informed consent document and proceeded to the questionnaire. Data were collected anonymously. IP addresses were used to identify and eliminate potential duplicate entries from the same user.

\section{Demographic Profiles}

A total of 47 completed the online questionnaire. 154 respondents completed the survey in paper form. Thus, 201 valid responses were used for testing the proposed model. The sample size requirements may differ in different types of statistical analysis, and a variety of opinions were also observed in the literature even when applying the same tools. In SEM-PLS reference for determination of sample size, many scholars recommend a sample size equivalent to 10 observations per model construct. There are 11 constructs in this study. The recommended sample size for this study should be more than 110 . The calculation of the sample size for conducting the structural equation model (SEM) shows that the recommended sample size for this study is 195 . In the calculation, the expected effect size was 0.3 , the number of latent variables was 11 , the number of observed variables was 44 , the p-value was set as 0.05 , and the statistical power was 0.8 . So, the sample size in this study (201) was more than the recommended sample size (195). The demographic characteristics of respondents are presented in Table 1. Most respondents were between the age 
of $65-69$ years old $(45.27 \%)$ or $70-74$ years old (36.8\%). A total of $65.17 \%$ of the sample was female. Although all our participants used smart phone, only $n=29(14.4 \%)$ indicated that they had used health applications related to nutrition advice, fall prevention, fitness, etc.

\section{Data Analysis and Results}

SmartPLS software was used for conducing structural equation model (SEM) using the partial least squares (PLS) path modeling method (124). This method allows to estimate the theory-based framework proposed in this study by measuring the latent variabes at observation level (i.e., measurement model) and testing the relationships that may exist between the latent variables on theoretical level (i.e., structural model). SEM is widely used in empirical studies on technology adoption to measure the theoretical validity (125). First, we conducted a measurement model analysis to ensure the validity and reliability of the instrument. Then, we conducted structural model analysis to test our hypotheses. In this section, we present our results for both analyses.

\section{Measurement Model}

According to Hair et al. (124), the measurement model needs to be assessed for internal consistency reliability, discriminant validity, and convergent validity to confirm the model fit. In this study, Cronbach's alpha (a), Dijkstra-Henseler's rho, and composite reliability were used to evaluate the internal consistency reliability. All constructs had Cronbach's alpha ranging from 0.842 to 0.950 , composite reliability values ranging from 0.895 to 0.968 , rho values ranging from 0.853 to 0.951 that are well above 0.7 , a minimum recommended thresholds for both of these measurement criteria $(124,126,127)$. Thus, based on measures provided in Table 2, all constructs have high internal consistency reliability.

Convergent validity assesses the degree to which different items used to measure the same construct agrees (128). We confirmed the convergent validity of our instrument using factor loadings and latent variables average variance extracted (AVE) values. While factor loadings are recommended to be higher than 0.6 (129) to ensure the convergent validity of the instrument, the AVE values are recommended to be higher than 0.5 (130). The factor loading values for each of the items are shown to be much higher than the recommended threshold. Similarly, the AVE values for each construct were also much higher than the recommended threshold, confirming a strong convergent validity of our measurement instrument.

The discriminant validity of the model was examined by following Chin's (131) recommendation to use the square root of the AVEs. To have a satisfactory level of discriminant validity, the square root of AVE should be higher than its correlation with other constructs in the model. The FornellLarcker criteria analysis is often used for discriminant validity, where the diagonal values need to be higher than the elements in the corresponding rows and columns to satisfy the conditions for discriminant validity. Table 3 presents the Fornell-Larcker analysis with the correlation matrix and the values of the square roots of AVEs. It is evident from the table that the measurement instrument used in this study sufficiently met the criteria of discriminant validity. We used another measuring criterion, the heterotrait-monotrait ratio of correlations (HTMT), to ensure the discriminant validity of our model. The HTMT is an upper boundary estimate for factor correlation and should be smaller than one [133]. Our results show HTMT values ranging between 0.319 and 0.806 that are much lower than the recommended threshold of one.

We examined the model fit using the results from bootstrap-based statistical analysis. The fit index Chi2 is commonly used in covariance based Structured Equation Modeling (SEM) to minimize the discrepancy function F. The purpose is to minimize the discrepancy between observed and reproduced covariance matrices. This fit index provides an assessment of how well the model reproduces the observed covariance matrix. As Partial Least Square (PLS) SEM, is based on variance based, Chi2 test is not useful. Instead, PLS-SEM uses t-statistics to find the best relationship between variable based on regression (132). In a PLS based SEM analysis, model fit relies on the bootstrap analysis to determine a discrepancy between the empirical and the model-implied correlation matrix [131]. We used the only approximate model fit criterion implemented for PLS path modeling, standardized root mean square residual (SRMR). SRMR is the square root of the sum of the squared differences between the model and empirical correlation matrix that is often used to determine approximate model fit in a PLS-SEM analysis. According to Hu and Bentler [132](133), a cut-off value of 0.08 indicates an acceptable fit for the model. Results from our bootstrap-based test show a SRMR value of 0.044 , which is much lower than the recommended acceptable value for a good model fit. Therefore, we believe that our measurement model has overall goodness of fit.

We have also tested the multicollinearity and common method bias, two common issues with any survey method study. We used the variance inflation factor (VIF) values as shown in Table 2 to rule out the multicollinearity issue. All but three items have a VIF values that are much lower than the recommended maximum threshold of 5 , an indication that multicollinearity is not an issue in our measurement instrument. In order to rule out common method bias, we conducted the Harman single-fact test as recommended by Podsakoff et al. (134) and found that no single factor is apparent in the un-rotated factor structure, which is an indication that common method bias is not an issue in this study.

\section{Structural Model and Hypothesis Testing}

We tested the hypotheses using three different models. First, we tested the original UTAUT2 model (Figure 1) to validate the applicability of the model in the healthcare context. Second, we tested using our proposed extended UTAUT2 model (Figure 2) with trust and antecedents of trust. Third, after evaluating the results of the second model analysis, we re-tested the data using our proposed simplified HTSA model (Figure 3 ). The predictive validity of our hypotheses was examined using the explanatory power and the significance of the paths as SEM-PLS analysis is known to not generate goodness of fit indices. In order to perform the path analyses for hypotheses testing, we used the SmartPLS software package 3.3.2 (125). 
To identify the hypothesized relationships among the factors in the study, the structural model was tested by path coefficients ( $\beta$ ), t-statistics, and pvalues. The results of the partial least square modelling, for the study's structural model, are presented in Table 4.

The results for original UTAUT2 (Model 1) show that the latent variables, performance expectancy, effort expectancy, social influence, facilitating condition, hedonic motivation, and price value, are all found to have no influence on individuals' intention to use $\mathrm{mHealth}$ services. On the other hand, only latent variable, habit, was found to have significant and strong influence on intention to continue to use mHealth services.

We then performed the same analysis using the extended UTAUT research model (Model 2). The results show that only one of the latent variables (Habit) from the original UTAUT model significantly influences intention to use of mHealth services with $\beta=0.572, t=3.684$, and $p=0.000$, supporting hypothesis $\mathrm{H} 5$. The results further show that the additional latent variable (Trust) also significantly influences the intention with $\beta=$ $0.164, t=1.967$, and $p=0.049$, supporting hypothesis $\mathrm{H} 8$ in our extended research model. The results show no support for the relationships between all other latent variables in the original UTAUT model and the dependent variable, intention. Thus, hypotheses $\mathrm{H} 1, \mathrm{H} 2, \mathrm{H} 3 \mathrm{a}, \mathrm{H} 6 \mathrm{a}$, and $\mathrm{H} 7 \mathrm{a}$ were not supported by model 2 analysis. For the relationships between trust construct and its antecedents, we found that social influence positively influences trust with $\beta=0.243, t=2.346$, and $p=0.019$; service quality has positive influence on trust with $\beta=0.401, t=3.926$, and $p=0.000$; and government policy also have positive influence on trust construct with $\beta=0.199, t=2.618$, and $p=0.009$. Thus, the proposed relationships between Trust and its three antecedents (Social Influence, Service Quality, and Government Policy) are all significant, supporting the hypotheses H3b, H9b, and H10b. Similarly, in exploring the relationships between habit and its antecedent factors, we found that both hedonic motivation and price value positively and significantly influence habit with $\beta=0.492, t=6.066$, and $p=0.000$; and $\beta=0.393, t=4.609$, and $p=0.000$, respectively. Thus, the proposed relationships between habit and its two antecedents (hedonic motivation and price value) are both significant, supporting the hypotheses $\mathrm{H} 6 \mathrm{~b}$ ad H7b. We found no support for service quality and government policy as antecedent factors for individuals' intention to continue to use mHealth services. Thus, $\mathrm{H} 9 \mathrm{a}$ and $\mathrm{H} 10 \mathrm{a}$ are not supported. Figure 4 below shows the path significant results for the extended UTAUT2 model.

Based on the findings from our first two model analyses, we proposed and tested a third (HTSA) model (Model 3). We believe that this simplified model provides a better and clear understanding about the formation of mHealth technology use intention among older population. The results show that both habit and trust significantly influence intention with $\beta=0.683, t=7.648$, and $p=0.000 ;$ and $\beta=0.259, t=2.415$, and $p=0.016$, respectively, confirming our hypotheses $\mathrm{H} 5$ and $\mathrm{H} 8$. The results further suggest that the proposed antecedents of trust are significant with $\beta=0.242$, $t=2.349$, and $p=0.019$ for social influence; $\beta=0.402, t=3.979$, and $p=0.000$ for service quality; and $\beta=0.200, t=2.607$, and $p=0.009$ for government policy. Thus, all three hypotheses $\mathrm{H} 3 \mathrm{~b}, \mathrm{H} 9 \mathrm{~b}$, and $\mathrm{H} 10 \mathrm{~b}$ are supported. Finally, for the antecedents of habit, the results show that the path between hedonic motivation and habit $(\beta=0.491, t=6.133$, and $p=0.00)$ and the path between price value and habit $(\beta=0.395, t=4.781$, and $p=$ 0.00 ) are significant, supporting both hypotheses $\mathrm{H} 6 \mathrm{~b}$ and $\mathrm{H} 7 \mathrm{~b}$. Therefore, all of the hypotheses in our proposed simplified HTSA model are found to be supported by our analyses. Figure 5 shows the path significant results for the proposed simplified UTAUT2 (HTSA) model.

\section{Discussion}

This study sought to understand underlying mechanisms in the formation of the behavioral intention of use mHealth services by elderly population. We laid out three specific goals for this study. First, we wanted to test the applicability of Venkatesh's (54) UTAUT2 model in the healthcare domain, specifically to explain mHealth use behavior by elderly population. Second, to fill a limitation of the UTAUT2 model by extending the model with inclusion of a technology trust component. Third, to propose a simplified model that could be more appropriate for explaining healthcare technology use behavior.

Among the seven UTAUT2 factors, all the hypotheses related to Performance Expectancy, effort expectancy, facilitating condition, social influence, hedonic motivation, and price value were rejected as the data analysis shows (Table 4). Only the hypothesis about habit was accepted among the seven core UTAUT2 factors. The rejections of the hypotheses related to the six core UTAUT2 factors indicate that UTAUT2 may not be reliable in explaining context-specific technology adoption and/or use behavior and results based on the model can vary greatly contextually. This inconsistency in results yielded by the UTAUT2 model is also reported in the meta-analytic study by Tamilmani et al. (135) when investigating the reliability of UTAUT2. Therefore, the authors believe that the UTAUT2 model's extension is crucial to better support efforts to find the influencing factors of technology adoption and use based on the contexts and type of technology use case. We further believe that extending the UTAUT model will strengthen the explanatory power of the model and it will be more applicable in the context-specific situations.

The analyses of our extended UTAUT2 research model resulted in similar findings as to the first analysis regarding the core UTAUT2 variables. Once again, the findings suggest that six of the core factors are not as important as antecedents for the behavioral intention in the context of healthcare technology. The finding in this study regarding the rejection of hypotheses about effort expectancy and price value aligns with the very recent finding by Alam et al. (82) in the Bangladesh context. The explanation of the weak influence of effort expectancy can be because the mHealth app interface is now more user friendly for the elderly (82). The non-significance of effort expectancy and performance expectancy aligns with the study by Moorthy et al. (136), where the applicability of the UTAUT2 model was also tested in educational settings for understanding mobile learning behaviors. Oliveira et al. (55) and Hu et al. (137) both reported that effort expectancy has no significant influence on behavioral intention in terms of technology adoption. To further explain the weak influence of price value, we believe that it might be because of the fact that healthcare is a 
necessary need in people lives and when the need for caring for own health is the highest concern for someone, the significance of price value becomes low.

Venkatesh et al. (47) reported that the influence of facilitating condition on behavioral intention becomes insignificant if both performance expectancy and effort expectancy are present in a research model, which is in line with our finding for the relationship between facilitating condition and intention. The study by Hoque and Sorwar (24) in Bangladesh reported insignificant association between these two factors, which also matches with the finding in this study. Furthermore, Oliveira et al. (138) and Talukder et al. (65) both reported an insignificant relationship between facilitating condition and intention Thus, the insignificant finding of the relationship between facilitating condition and behavioral intention is also in consistent with some of the findings by other researchers. This finding can be described as a reason that the elderly is mostly introduced with the use of mHealth by others, such as family members. Therefore, they may not have to be worried about technical and other requirements.

We found that social influence is an insignificant predictor of behavioral intention, which is also in consistent with the finding from Oliveira et al. (138). The findings also show that there is no strong relationship between hedonic motivation and Behavioral Intention. This is also consistent with previous studies by Oliveira et al. (138) and Metha et al. (80). Additionally, the finding of rejection of hedonic motivation as a strong determinant for behavioral intention is in line up with the study by Dwivedi et al. (64) in the USA and Canada context. It might indicate that elderly users are more concerned about the usefulness and benefits than fun and excitement about using the mHealth app.

To identify the factors that might influence the behavioral intention to use mHealth adoption by the elderly population, this study used the UTAUT2 model by extending it further by adding three factors named service quality, government policy, and Trust. Our model analysis further confirmed some of the concerns by other researchers about the lack of trust concept in UTAUT model. Our results show that trust is one of the two significant factors that shape an individual's behavioral intention for the use of mHealth services. Among the three other factors added to the UTAUT2 model, the fact that service quality, social influence, and government policy were all found to be a strong determinant of Trust and insignificant determinants of intention; it implies that Trust is a stronger antecedent of behavioral intention than service quality, social influence, and government policy. Therefore, Trust should be used as a mediating factor for the relationship between these three antecedent variables and behavioral intention. The strong relationship between service quality and trust is also supported by Cao et al. (139),(140-142) (139), Kundu and Datta (2015), Lien et al. (2014) and Qalati et al. (2021). Our finding of the relationships between social influence and users' trust is also supported by previous studies(143145) studies (Zhang et al. (2020), Shin (2013) and Li, Hess and Valacich (2006)). The findings of our studies about the influence of government health policy on user's trust are supported by previous studies(Mansoor, 2021, Li and Xue (2021), Horst, Kuttschreuter and Gutteling, 2007)) (146148) those also reported a significant positive relationship between government health policy and user's trust.

Findings of our study show a strong relationship between habit and its antecedents, price value and hedonic motivation, which is supported by previous studies. For example, Isa and Palpanadan (2020), Uddin et al. (2019), and Sweeney and Sharmin (2020)(149-151) indicate that users' habit of consumption is sensitive to price. Similarly, the significant influence of hedonic motivation on habit is supported by Khatimah, Susanto and Abdullah (2019)(77).

Moreover, this study has taken a positive approach in exploring the role of Trust in influencing the behavioral intention to use mHealth. It was shown to have a positive effect. While lack of trust has been found to be a barrier for the elderly in behavioral intention of technology (123), trust in technology, on the other hand, can influence elderly online health-related activities (97). Furthermore, in studying the acceptance of the mHealth service by the users of different age-group, Guo et al. (152) exhibit that Trust significantly shows both mediating and direct effect on adoption intention, which supports the finding of this study about Trust.

The result of habit matches to those observed in earlier studies. Consumers' habit has a significant impact on technology use, both directly and as an intended path to affect behavior $(54,68)$. Limayem et al. $(153)$ also found that habit exerts a moderating effect between intention and information systems usage behavior. The findings of the present study are consistent with past studies in their impact on behavioral intention. Also, comparatively the recent work by Sergueeva et al. (154) reported that habit is a significant determinant of wearable adoption. Therefore, the focus on the role of habit on behavioral intention would be worthwhile for mHealth providers' service.

Based on the findings in our second (extended UTAUT2) model, we proposed and tested a third model that is simplified and we believe more appropriate and applicable to the context of this study. This model analysis revealed interesting findings compared to the previous two models. The empirical evidence of the original UTAUT2 model found only one out of seven antecedents for behavioral intention as significant with R2 $=0.628$. Our proposed simplified model incorporated a technology trust belief to the original UTAUT2 model that resulted in a much better explanatory power. As the results for the extended model showed that only one of the factors from the original UTAUT2 was significant, our simplified model only kept the one factor from original UTAUT2 model along with the new factor (technology trust belief) as antecedents for behavioral intention. Together, these two factors can explain $70.1 \%(R 2=.701)$ of the variances for use intention. This is a significant improvement from the original UTAUT2 model results. This high variance for Trust also indicates that the extension of the UTAUT2 model by adding Trust (TR) has increased the model fitness in ultimately explaining the variance in behavioral intention (BI) for use of mHealth services by elderlies. The extended model analysis further suggests antecedents for both habit and trust. The R2 value of 0.525 for trust suggests that all the independent factors social influence, service quality, and government policy can explain up to $52.5 \%$ of the variance in Trust which ultimately influences the behavioral intention to use of 
mHealth services. The R2 value of 0.601 for habit further suggests that the two antecedent factors price value and hedonic motivation together explain $60 \%$ of the variances in forming a habit, which also in turn helps to better explain behavioral intention for using mHealth services.

\section{Implications Of The Results}

There are on-going debates about the formation of individuals' intention to use healthcare technologies and their services (155, 156). Recent research also cast doubt about the utility of UTAUT model for understanding people's technology-specific use behavior (65, 135, 157). The findings of this study shed in-depth insights into this debate and provide with clear direction about the applicability of UTAUT model for context-specific technology adoption and use behavior. This study makes several key theoretical and practical contributions in the technology adoption and diffusion domain.

\section{Theoretical contribution}

First, this study addresses a major concern and a gap in the UTAUT model by incorporating trust belief. Although the UTAUT2 model was developed by combining eight competing theories from the technology acceptance domain, the model lacks a very important component of technology adoption, which is technology trust. A large body of researchers (see for example: $85,158,159$ ) agree that one of the biggest motivators to utilize sensitive technologies (such as mHealth) is individuals' trust in the specific technology. UTAUT is missing this important construct and, thus, shows limitation in explaining technology adoption and use behavior. This study addresses this missing concept by extending the UTAUT2 model by incorporating trust and its antecedent factors. We show that the addition of trust component significantly improves the explanatory power of the UTAUT2 model for technology adoption and further diffusion.

Second, this study also makes a significant theoretical contribution to the domain of technology adoption by proposing a simplified healthcare technology service acceptance (HTSA) model. Based on our findings from the analyses of the original UTAUT2 model and the proposed extended UTAUT model (Model 2), we proposed a more simplified model (HTSA model) that we believe is more appropriate for explaining people's healthcare technology use intention behavior. Venkatesh et al. (53) called for a paradigm shift of UTAUT extensions in technology acceptance and use. Because "context has become one of the important theoretical lenses" in Information Systems research (53), the authors of UTAUT further recommended using this model using the theoretical notion of contextualization. Responding to the call for contextualization of UTAUT2 model, we believe that our simplified model is a step forward in the contextualization of UTAUT2 model for understanding the use behavior of mHealth services by elderly population.

Third, though the UTAUT was developed primarily to explain technology acceptance and use behavior by individuals within organizations (53), the model has been studied for testing the applicability in a non-organization setting, such as patients' voluntary use of mHealth services. Our findings suggest that although UTAUT2 provides critical ground for context-specific and voluntary technology use behavior, the model as proposed is insufficient to provide a complete explanation of the voluntary use behavior. Our proposed extended model and the simplified model show better results in explaining such voluntary technology use and context-specific technology use behavior.

Four, the applicability of the UTAUT2 model for understanding the use of technology is largely unknown in existing technology adoption literature, specifically in the healthcare technology adoption domain. This study provides important stride to fill this void in the existing literature by providing empirical evidence. To do so, we not only tested the original UTAUT2 model, but also, proposed and studied two additional models (extended UTAUT2 model and simplified UTAUT model) derived from the original model. Our analyses of the three different models provide important direction needed for future researchers in studying technology use behavior.

Five, another known shortfall of the UTAUT2 model is that it does not take into consideration of cultural factors even though some studies suggest a significant role of culture on technology adoption (52). This study addresses this theoretical gap by including social influence and government policy as antecedent factors of technology trust belief. Our findings suggest that these factors are important in shaping individual's technology related trust beliefs which in turn influences technology use behavior. In addition, the rejection of the hypotheses in six out of seven factors in the original UTAUTS model indicates the extension of the UTAUTS model is crucial to identify different influencing factors of technology adoption based on the contexts and type of technology.

\section{Practical contribution}

This study reflects several practical implications.

The study has taken a positive approach in exploring the role of trust in influencing the behavioral intention to use mHealth and provides valuable implications for government and healthcare organizations. Unlike findings in other studies, the empirical findings in this study provide an important and new approach in understanding the impact of technology-specific trust belief and suggests considering trust as a powerful mediating factor in the relationship between the service quality and behavioral intention, social influence and behavioral intention as well as in the relationship between government policy and behavioral intention. Based on the relatively distinct and new finding in this study, the authors convincingly suggest that if the government policymakers try to increase the trust level of the elderlies in Hong Kong through social influence, service quality, and government 
policy along with trying to increase the habit in using new technology to ultimately enhance behavior intention for mHealth services usage. Practical implications of the findings can be further elaborated as below:

First, mhealth services providers need to increase the trust level of elderly people by showing their achievement, skills and reliability as well as improving app design and presenting the advantages of their services better. Doing so will increase the cognitive trust of elderlies. Also, for improving service quality, which is an antecedent of trust, mHealth services providers should apply advanced data-mining techniques to deliver highly personalized services and content. On the other hand, the mHealth service providers should be aware of the fact that the elderlies are less likely to develop trust in mHealth services unless they are aware of the advantage of using mHealth services over hospital services.

Second, mHealth service providers are encouraged to collaborate with health care or community service providers trusted by older people when marketing their mHealth services to elderly users. It may lead to higher adoption rates than simply promoting mHealth services in isolation.

Third, mHealth service providers are urged to employ age-friendly strategies to design mhealth services that can fit older people with different levels of digital health literacy. It can promote their service quality to establish a trusting relationship between service providers and older users.

Fourth, the government should undertake the responsibility to reinforce the safety and effectiveness of mHealth services. The government should formulate regulations to govern the mHealth services providers. This policy indicates that the government supports and monitors the development of mHealth services. It can also enhance older people's confidence in adopting mHealth services in their daily life.

Finally, the findings in this study show that trust should be considered as a strong influence on elderly Chinese's behavioral intention of using mHealth services. Therefore, strategies should be implemented by practitioners to increase their level of trust, through social influence, service quality, and government policy along with trying to increase the habit of using new technology such as mHealth services.

Table 5 below shows the summary of the theocratical and practical contributions discussed above.

\section{Limitations Of The Study}

Although the findings of this study are very interesting, encouraging, and useful for both practitioner and researchers, we feel that several limitations must be addressed. First, the findings of this study may not be generalizable to a broader age population as the source of data was mostly from elderly people who are 65 years or older. Additionally, our study focused on elderly population in Hong Kong and, thus, the results may not be generalizable to a broader geographical population. Future study may include a more heterogeneous group of samples from broader range of age and geographical regions. The second limitation is that we used self-reported surveys for this study. Although self-reported surveys are popular and widely used by research community for studying technology adoption research, this method of collecting data is known to contribute many different biases in the study results (160). In addition, our participants were either referred by the community centres or scanned the QR code on the flyers by the participants themselves. Thus, we could not calculate the response rate with these data collection methods. Future studies can be designed to avoid these biases as well as appropriate steps can be taken to mitigate some of these biases. The third limitation of this study comes from the contextualization of a specific technology. This study was conducted in the context of mHealth services and the results may not be applicable to understand behavioral intention for using other healthcare technologies and their associated services (e.g., EHR, PHR, etc.). Additional study must be conducted to test the validity of our proposed simplified HTSA model in a broader technological, geographical, and population settings.

\section{Conclusion}

As technologies are increasingly integrated into our lives, it is paramount that we establish a clear understanding of their adoption and diffusion mechanisms. As the world is experiencing the catastrophic impact of the COVID-19 pandemic, technologies are emerging as an alternative option to conduct daily businesses. From purchasing groceries to meeting with personal doctors, we learn to use technologies in every aspect in our lives. However, the questions remained unanswered as to what motivates people to voluntarily adopt and continue to use certain technologies? Specifically, how can we get elderly population (the most vulnerable group due to pandemic) to utilize different technological services without needing to have physical contacts? This study addresses these questions by focusing on understanding the behavioral mechanism for forming the intention to continue to use mHealth services by elderly population. We grounded this study using UTAUT2 theory in an effort to understand its applicability in explaining health technology use behavior.

In the study, we analyzed the responses using three different research models - the original UTAUT2 model, an extended UTAUT2 model, and a simplified UTAUT2 (HTSA) model. The results of our analyses revealed interesting results where six of the seven factors in the original UTAUT2 were found to be insignificant in explaining use behavior of healthcare technology. Those insignificant factors in the UTAUT2 and extended UTAUT2 model were performance expectancy, effort expectancy, facilitating condition, social influence, hedonic motivation, and price value. In contrast, it was found that only trust and habit showed influence on the behavioral intention for the use of mHealth services by elderlies. Then, during the test of the HTSA model, it was found that service quality, social influence, and government policy were the strong determinants of trust and insignificant determinants of behavioral intention. Hence, the authors conclude that trust should be used as a mediating factor for the relationships between service quality, social influence, and government policy and behavioral intention. 
When testing and validating, the extended UTAUT2 model that showed a better performance in explaining behavioral intent than the original UTAUT2 model. Then, based on our findings of the first two model analyses, we further proposed and validated a third model (HTSA model) that is more simplified version of the extended UTAUT model. The third model showed better performance than the original UTAUT2 model in explaining behavioral intention to continue to use mHealth services by the elderly population in Hong Kong. This study is significant, and its findings are new because the authors used the UTAUT2 model to explain the factors affecting behavioral intention but ended up with new findings based on a newly devised simplified version of the UTAUT2 model that no studies have used before.

We believe these findings are both interesting and novel and provide an in-depth understanding of the formation of healthcare technologies use behavior. A future study could confirm whether the findings based on the new model devised in this study can explain the behavioral intention to continue to use mHealth services by the other parts of the population as well as the population of other age groups. In the end, we believe that this study is very timely as technologies are becoming essential part of healthcare delivery due to ongoing COVID-19 pandemic and face-to-face service restrictions.

\section{List Of Abbreviations}

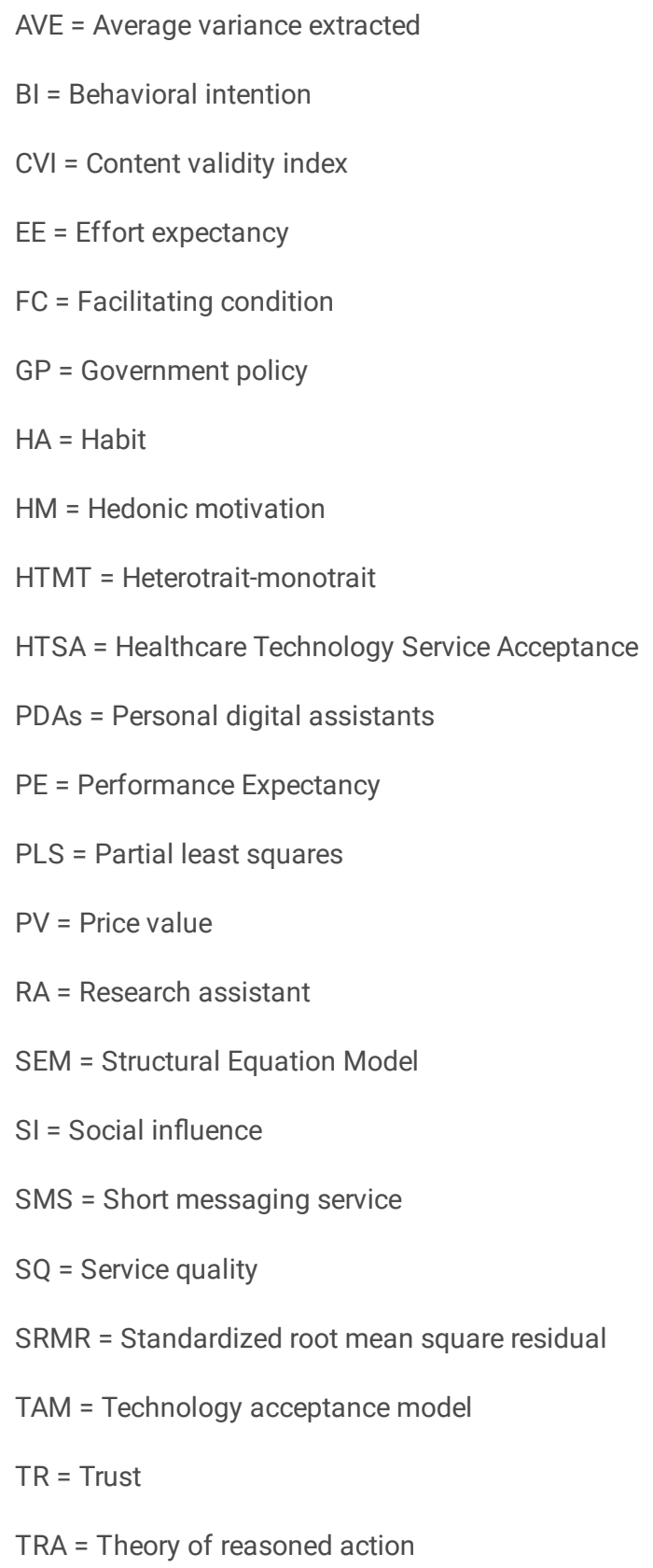


WHO $=$ World Health Organization

\section{Declarations}

Institutional Review Board Statement: Ethical approval for this study was obtained from The Human Subjects Ethics Committee of The Hong Kong Polytechnic University (HSEARS20170428006). Permission to conduct the study was also sought from the person in charges of the community center for older people.

Informed Consent Statement: Informed consent was obtained from all subjects involved in the study. Digital written informed consent has been obtained from the participants to publish this paper.

Data Availability Statement: Data is not available for public access.

Competing Interests: The authors declare that they have no competing interests.

Funding: This research did not receive any specific grant from funding agencies in the public, commercial, or not-for-profit sectors.

Author Contributions: All authors developed the original concept and drafted the manuscript. G.S and S.R wrote the final manuscript. J.Y.W. L was accountable for data collection and the quality control aspect of the study throughout the study. S.R and R.H commented on the statistical data analysis. All authors provided overall comments on the manuscript and have read and agreed to the published version of the manuscript.

Acknowledgements: Not applicable.

\section{References}

1. WHO. Global strategy and action plan on ageing and health. World Health Organization; 2017.

2. Jones K. The Problem of an Aging Global Population, Shown by Country 2020 [Available from: https://www.visualcapitalist.com/aging-globalpopulation-problem/.

3. Gong E, Gu W, Luo E, Tan L, Donovan J, Sun C, et al. Development and Local Contextualization of Mobile Health Messages for Enhancing Disease Management Among Community-Dwelling Stroke Patients in Rural China: Multimethod Study. JMIR mHealth and uHealth. 2019;7(12):e15758.

4. Wang H, Zhao Y, Yu L, Liu J, Zwetsloot IM, Cabrera J, et al. A personalized health monitoring system for community-dwelling elderly people in Hong Kong: design, implementation, and evaluation study. Journal of medical internet research. 2020;22(9):e19223.

5. Wong AKC, Wong FKY, Chang KKP. A Proactive Mobile Health Application Program for Promoting Self-Care Health Management among Older Adults in the Community: Study Protocol of a Three-Arm Randomized Controlled Trial. Gerontology. 2020;66(5):506-13.

6. WHO. mHealth: New horizons for health through mobile technologies. World Health Organization; 2011.

7. Changizi M, Kaveh MH. Effectiveness of the mHealth technology in improvement of healthy behaviors in an elderly population-a systematic review. Mhealth. 2017;3.

8. Azhar FAB, Dhillon JS, editors. A systematic review of factors influencing the effective use of mHealth apps for self-care. 20163 rd International Conference on Computer and Information Sciences (ICCOINS); 2016: IEEE.

9. Mileski M, Kruse CS, Catalani J, Haderer T. Adopting telemedicine for the self-management of hypertension: systematic review. JMIR medical informatics. 2017;5(4):e6603.

10. Alsswey A, Al-Samarraie H. Elderly users' acceptance of mHealth user interface (UI) design-based culture: the moderator role of age. Journal on Multimodal User Interfaces. 2020;14(1):49-59.

11. Liu K, Xie Z, Or CK. Effectiveness of mobile App-Assisted self-care interventions for improving patient outcomes in type 2 diabetes and/or hypertension: systematic review and meta-analysis of randomized controlled trials. JMIR mHealth and uHealth. 2020;8(8):e15779.

12. Marcussen L. Promotion of Active and Healthy Ageing through mHealth for Healthy Older Adults: a scoping review 2020.

13. Klaver NS, van de Klundert J, Askari M. Relationship between perceived risks of using mHealth applications and the intention to use them among older adults in the Netherlands: cross-sectional study. JMIR mHealth and uHealth. 2021;9(8):e26845.

14. Xie Z, Kalun Or C, editors. Acceptance of mHealth by Elderly Adults: A Path Analysis. Proceedings of the Human Factors and Ergonomics Society Annual Meeting; 2020: SAGE Publications Sage CA: Los Angeles, CA.

15. OGCIO. Two-year ICT Outreach Programme for the Elderly 2018-19: Office of the Government Chief Information Officer; 2019 [Available from: https://www.ogcio.gov.hk/en/our_work/community/ict_programmes_for_elderly/2018-19/.

16. Alaiad A, Zhou L. The determinants of home healthcare robots adoption: An empirical investigation. International journal of medical informatics. 2014;83(11):825-40. 
17. Postema T, Peeters J, Friele R. Key factors influencing the implementation success of a home telecare application. International journal of medical informatics. 2012;81(6):415-23.

18. Moudud-Ul-Huq S, Swarna RS, Sultana M. Elderly and middle-aged intention to use m-health services: an empirical evidence from a developing country. Journal of Enabling Technologies. 2021.

19. Jen W-Y, Hung M-C. An empirical study of adopting mobile healthcare service: the family's perspective on the healthcare needs of their elderly members. Telemedicine and e-Health. 2010;16(1):41-8.

20. Deng Z, Mo X, Liu S. Comparison of the middle-aged and older users' adoption of mobile health services in China. International journal of medical informatics. 2014;83(3):210-24.

21. Chen K, Chan A. Gerontechnology acceptance by elderly Hong Kong Chinese: a senior technology acceptance model (STAM). Ergonomics. 2014;57(5):635-52.

22. Chen K, Chan A. Predictors of gerontechnology acceptance by older Hong Kong Chinese. Technovation. 2014;34(2):126-35.

23. Ma Q, Chan A, Chen K. Personal and other factors affecting acceptance of smartphone technology by older Chinese adults. Applied ergonomics. 2016;54:62-71.

24. Hoque R, Sorwar G. Understanding factors influencing the adoption of mHealth by the elderly: An extension of the UTAUT model. International journal of medical informatics. 2017;101:75-84.

25. Best R, Souders DJ, Charness N, Mitzner TL, Rogers WA, editors. The role of health status in older adults' perceptions of the usefulness of ehealth technology. International Conference on Human Aspects of IT for the Aged Population; 2015: Springer.

26. Cimperman M, Brenčič MM, Trkman P. Analyzing older users' home telehealth services acceptance behavior-applying an Extended UTAUT model. International journal of medical informatics. 2016;90:22-31.

27. Mahmood SAI. Health systems in Bangladesh. Health Systems and Policy Research. 2012;1(1):1-4.

28. Osman FA. Health policy, programmes and system in Bangladesh: achievements and challenges. South Asian Survey. 2008;15(2):263-88.

29. Sülz S, van Elten HJ, Askari M, Weggelaar-Jansen AM, Huijsman R. eHealth Applications to Support Independent Living of Older Persons: Scoping Review of Costs and Benefits Identified in Economic Evaluations. Journal of medical Internet research. 2021;23(3):e24363.

30. Bloom G, Berdou E, Standing H, Guo Z, Labrique A. ICTs and the challenge of health system transition in low and middle-income countries. Globalization and health. 2017;13(1):1-10.

31. Meng F, Guo X, Zhang X, Peng Z, Lai K-H, editors. Examining the role of technology anxiety and health anxiety on elderly users' continuance intention for mobile health services use. Proceedings of the 53rd Hawaii International Conference on System Sciences; 2020.

32. Khan T, Khan KD, Azhar MS, Shah SNA, Uddin MM, Khan TH. Mobile health services and the elderly: Assessing the determinants of technology adoption readiness in Pakistan. Journal of Public Affairs.e2685.

33. Meng F, Guo X, Peng Z, Ye Q, Lai K-H. Trust and elderly users' continuance intention regarding mobile health services: the contingent role of health and technology anxieties. Information Technology \& People. 2021.

34. Noorbergen TJ, Adam MT, Roxburgh M, Teubner T. Co-design in mHealth systems development: insights from a systematic literature review. AIS Transactions on Human-Computer Interaction. 2021;13(2):175-205.

35. Kabir ZN, Leung AYM, Grundberg Å, Boström A-M, Lämås K, Kallström AP, et al. Care of family caregivers of persons with dementia (CaFCa) through a tailor-made mobile app: study protocol of a complex intervention study. BMC geriatrics. 2020;20(1):1-7.

36. Vázquez-de Sebastián J, Ciudin A, Castellano-Tejedor C. Analysis of Effectiveness and Psychological Techniques Implemented in mHealth Solutions for Middle-Aged and Elderly Adults with Type 2 Diabetes: A Narrative Review of the Literature. Journal of Clinical Medicine. 2021;10(12):2701.

37. Dalmau Guasp A. Effectivity of mHealth technologies to reduce sedentary behavior in an elderly population: a clinical trial. 2021.

38. McGarrigle L, Boulton E, Todd C. Map the apps: a rapid review of digital approaches to support the engagement of older adults in strength and balance exercises. BMC geriatrics. 2020;20(1):1-11.

39. Turnbull ML, Jin Y, Yau AH, Lai MS, Cheung MY, Kwan WYW, et al. mHealth in hyper-connected Hong Kong: examining attitudes and access to mobile devices and health information among older Chinese residents. Mhealth. 2021;7.

40. Lan Z, Liu H, Yang C, Liu X, Sorwar G, editors. Investigating Influencing Factors of Chinese Elderly Users' Intention to Adopt MHealth Based on the UTAUT2 Model. Proceedings of the Fourth International Conference on Biological Information and Biomedical Engineering; 2020.

41. Duarte P, Pinho JC. A mixed methods UTAUT2-based approach to assess mobile health adoption. Journal of Business Research. 2019;102:14050.

42. Dhiman N, Arora N, Dogra N, Gupta A. Consumer adoption of smartphone fitness apps: an extended UTAUT2 perspective. Journal of Indian Business Research. 2019.

43. Tavares J, Oliveira T. Electronic health record portals definition and usage. Encyclopedia of E-Health and Telemedicine: IGI Global; 2016. p. 55562. 
44. Chiu C-M, Wang ET. Understanding Web-based learning continuance intention: The role of subjective task value. Information \& Management. 2008;45(3):194-201.

45. Marchewka JT, Kostiwa K. An application of the UTAUT model for understanding student perceptions using course management software. Communications of the IIMA. 2007;7(2):10.

46. Nuq PA, Aubert B. Towards a better understanding of the intention to use eHealth services by medical professionals: The case of developing countries. International Journal of Healthcare Management. 2013;6(4):217-36.

47. Venkatesh V, Morris MG, Davis GB, Davis FD. User Acceptance of Information Technology: Toward a Unified View. MIS Quarterly. 2003;27(3):425 $-78$.

48. Magsamen-Conrad K, Wang F, Tetteh D, Lee Y-I. Using technology adoption theory and a lifespan approach to develop a theoretical framework for eHealth literacy: extending UTAUT. Health communication. 2020;35(12):1435-46.

49. Liang H, Xue Y, Ke W, Wei KK. Understanding the Influence of Team Climate on IT Use. Journal of the Association for Information Systems. 2010;11(8):414 - 32.

50. Chang I-C, Hwang H-G, Hung W-F, Li Y-C. Physicians' acceptance of pharmacokinetics-based clinical decision support systems. Expert systems with applications. 2007;33(2):296-303.

51. Kijsanayotin B, Pannarunothai S, Speedie SM. Factors influencing health information technology adoption in Thailand's community health centers: Applying the UTAUT model. International Journal of Medical Informatics. 2009;78(6):404 - 16.

52. Im I, Hong S, Kang MS. An international comparison of technology adoption: Testing the UTAUT model. Information \& management. 2011;48(1):1-8.

53. Venkatesh V, Thong JY, Xu X. Unified theory of acceptance and use of technology: A synthesis and the road ahead. Journal of the association for Information Systems. 2016;17(5):328-76.

54. Venkatesh V, Thong JY, Xu X. Consumer acceptance and use of information technology: extending the unified theory of acceptance and use of technology. MIS quarterly. 2012:157-78.

55. Oliveiraa T, Fariaa M, Thomasb MA, Popovic A. Extending the understanding of mobile banking adoption: When UTAUT meets TTF and ITM. International Journal of Information Management. 2014;34:689-703.

56. Woldeyohannes HO, Ngwenyama OK, editors. Factors influencing acceptance and continued use of mHealth apps. International Conference on $\mathrm{HCl}$ in Business, Government, and Organizations; 2017: Springer.

57. Sezgin E, Özkan-Yildirim S, Yildirim S. Investigation of physicians' awareness and use of mHealth apps: A mixed method study. Health Policy and Technology. 2017;6(3):251-67.

58. Sun Y, Wang N, Guo X, Peng Z. Understanding the Acceptance of Mobile Health Services: A Comparison and Integration of Alternative Models. Journal of Electronic Commerce Research. 2013;14(2):183 - 200.

59. Breil B, Kremer L, Hennemann S, Apolinário-Hagen J, editors. Acceptance of mHealth Apps for Self-Management Among People with Hypertension. GMDS; 2019.

60. Karahanna E, Straub DW, Chervany NL. Information technology adoption across time: A cross-sectional comparison of pre-adoption and postadoption beliefs. MIS quarterly. 1999;23(2).

61. Venkatesh V, Davis FD. A theoretical extension of the technology acceptance model: four longitudinal field studies. Management Science. 2000;46(2):186 - 204.

62. Quaosar GAA, Hoque MR, Bao Y. Investigation on the precursors to and effects of human resource information system use: The case of a developing country. Cogent Business \& Management. 2018;5(1):1485131.

63. Czaja SJ, Charness N, Fisk AD, Hertzog C, Nair SN, Rogers WA, et al. Factors predicting the use of technology: findings from the Center for Research and Education on Aging and Technology Enhancement (CREATE). Psychology and Aging. 2006;21(2):333 - 52.

64. Dwivedi YK, Shareef MA, Simintiras AC, Lal B, Weerakkody V. A generalised adoption model for services: A cross-country comparison of mobile health (m-health). Government Information Quarterly. 2016;33(1):174-87.

65. Talukder MS, Sorwar G, Bao Y, Ahmed JU, Palash MAS. Predicting antecedents of wearable healthcare technology acceptance by elderly: A combined SEM-Neural Network approach. Technological Forecasting and Social Change. 2020;150:119793.

66. Ajzen I. Residual effects of past on later behavior: Habituation and reasoned action perspectives. Personality and social psychology review. 2002;6(2):107-22.

67. Gefen D. TAM or just plain habit: A look at experienced online shoppers. Journal of Organizational and End User Computing (JOEUC). 2003;15(3):1-13.

68. Yuan S, Ma W, Kanthawala S, Peng W. Keep using my health apps: Discover users' perception of health and fitness apps with the UTAUT2 model. Telemedicine and e-Health. 2015;21(9):735-41.

69. Venkatesh V, Morris MG, Ackerman PL. A longitudinal field investigation of gender differences in individual technology adoption decisionmaking processes. Organizational behavior and human decision processes. 2000;83(1):33-60. 
70. Alsharo M, Alnsour Y, Alabdallah M. How habit affects continuous use: evidence from Jordan's national health information system. Informatics for Health and Social Care. 2020;45(1):43-56.

71. Raman A, Don Y. Preservice teachers' acceptance of learning management software: An application of the UTAUT2 model. International Education Studies. 2013;6(7):157-64.

72. Goulão APBA. E-Health individual adoption-empirical model based on UTAUT 22014.

73. Brown SA, Venkatesh V. Model of adoption of technology in households: A baseline model test and extension incorporating household life cycle. MIS quarterly. 2005:399-426.

74. Alalwan AA, Dwivedi YK, Rana NP, Lal B, Williams MD. Consumer adoption of Internet banking in Jordan: Examining the role of hedonic motivation, habit, self-efficacy and trust. Journal of Financial Services Marketing. 2015;20(2):145-57.

75. Sudbury D, Saeed A, Nnajiuba U, Murugesh-Warren A, Mashayekhi S, Abdel-Gadir S, et al., editors. An extension of the UTAUT 2 in a healthcare context. UKAIS; 2013.

76. Gao Y, Li H, Luo Y. An empirical study of wearable technology acceptance in healthcare. Industrial Management \& Data Systems. 2015.

77. Khatimah H, Susanto P, Abdullah NL. Hedonic motivation and social influence on behavioral intention of e-money: The role of payment habit as a mediator. International Journal of Entrepreneurship. 2019;23(1):1-9.

78. Chiu C-M, Hsu M-H, Lai H, Chang C-M. Re-examining the influence of trust on online repeat purchase intention: The moderating role of habit and its antecedents. Decision Support Systems. 2012;53(4):835-45.

79. Aw EC-X, Basha NK, Ng SI, Sambasivan M. To grab or not to grab? The role of trust and perceived value in on-demand ridesharing services. Asia Pacific Journal of Marketing and Logistics. 2019.

80. Mehta A, Morris NP, Swinnerton B, Homer M. The influence of values on E-learning adoption. Computers \& Education. 2019;141:103617.

81. Chen H-J, Sun T-H. Clarifying the impact of product scarcity and perceived uniqueness in buyers' purchase behavior of games of limited-amount version. Asia Pacific Journal of Marketing and Logistics. 2014.

82. Alam MZ, Hoque MR, Hu W, Barua Z. Factors influencing the adoption of mHealth services in a developing country: A patient-centric study. International Journal of Information Management. 2020;50(February):128-43.

83. Rasmi M, Alazzam MB, Alsmadi MK, Almarashdeh IA, Alkhasawneh RA, Alsmadi S. Healthcare professionals' acceptance Electronic Health Records system: Critical literature review (Jordan case study). International Journal of Healthcare Management. 2018:1-13.

84. Loewenstein G, Price J, Volpp K. Habit formation in children: Evidence from incentives for healthy eating. Journal of health economics. 2016;45:47-54.

85. Gefen D, Benbasat I, Pavlou P. A research agenda for trust in online environments. Journal of Management Information Systems. 2008;24(4):275-86.

86. Mcknight DH, Carter M, Thatcher JB, Clay PF. Trust in a specific technology: An investigation of its components and measures. ACM Transactions on management information systems (TMIS). 2011;2(2):1-25.

87. Bhattacherjee A. Individual trust in online firms: Scale development and initial test. Journal of management information systems. 2002;19(1):211-41.

88. Pavlou PA. Consumer Acceptance of Electronic Commerce: Integrating Trust and Risk with the Technology Acceptance Model. International Journal of Electronic Commerce. 2003;7(3):101-34.

89. Carter L, Bélanger F. The utilization of e-government services: citizen trust, innovation and acceptance factors. Information systems journal. 2005;15(1):5-25.

90. Gefen D, Srinivasan Rao V, Tractinsky N, editors. The conceptualization of trust, risk and their electronic commerce: the need for clarifications. System Sciences, 2003 Proceedings of the 36th Annual Hawaii International Conference on; 2003: IEEE.

91. Kim DJ, Ferrin DL, Rao HR. A Trust-based Consumer Decision-Making Model in Electronic Commerce: The Role of Trust, Perceived Risk, and their Antecedents. Decision Support Systems. 2008;44(2):544 - 64.

92. Li X, Hess TJ, Valacich JS. Why do we trust new technology? A study of initial trust formation with organizational information systems. The Journal of Strategic Information Systems. 2008;17(1):39-71.

93. Lankton NK, McKnight DH, Tripp J. Technology, humanness, and trust: Rethinking trust in technology. Journal of the Association for Information Systems. 2015;16(10):1.

94. Bansal G, Zahedi F, Gefen D. The Impact of Personal Dispositions on Information Sensitivity, Privacy Concern and Trust in Disclosing Health Information Online. Decision Support Systems. 2010;49(2):138 - 50.

95. Malhotra NK, Kim SS, Agarwal J. Internet Users' Information Privacy Concerns (IUIPC): The Construct, the Scale, and a Aausal Model. Information Systems Research. 2004;15(4):336 - 55.

96. Söderström E, Eriksson N, Åhlfeldt R-M. Managing healthcare information: analyzing trust. International journal of health care quality assurance. 2016. 
97. Zulman DM, Kirch M, Zheng K, An LC. Trust in the internet as a health resource among older adults: analysis of data from a nationally representative survey. Journal of medical Internet research. 2011;13(1):e19.

98. Meng F, Guo X, Peng Z, Lai K-H, Zhao X. Investigating the adoption of mobile health services by elderly users: Trust transfer model and survey study. JMIR mHealth and uHealth. 2019;7(1):e12269.

99. Ganguli S, Roy SK. Generic technology-based service quality dimensions in banking: Impact on customer satisfaction and loyalty. International journal of bank marketing. 2011;29(2):168-89.

100. ZeithamI VA. Consumer perceptions of price, quality, and value: a means-end model and synthesis of evidence. Journal of marketing. $1988 ; 52(3): 2-22$.

101. Zeithaml VA, Berry LL, Parasuraman A. The behavioral consequences of service quality. Journal of marketing. 1996;60(2):31-46.

102. Delone WH, McLean ER. The DeLone and McLean model of information systems success: a ten-year update. Journal of management information systems. 2003;19(4):9-30.

103. Cronin Jr JJ, Taylor SA. Measuring service quality: a reexamination and extension. Journal of marketing. 1992;56(3):55-68.

104. Dabholkar PA, Shepherd CD, Thorpe DI. A comprehensive framework for service quality: an investigation of critical conceptual and measurement issues through a longitudinal study. Journal of retailing. 2000;76(2):139-73.

105. Akter S, Ray P, D’Ambra J. Continuance of mHealth services at the bottom of the pyramid: the roles of service quality and trust. Electronic Markets. 2013;23(1):29-47.

106. Dagger TS, Sweeney JC, Johnson LW. A hierarchical model of health service quality: scale development and investigation of an integrated model. Journal of service research. 2007;10(2):123-42.

107. Foster BD, Cadogan JW. Relationship selling and customer loyalty: an empirical investigation. Marketing intelligence \& planning. 2000.

108. Coulter KS, Coulter RA. The effects of industry knowledge on the development of trust in service relationships. International Journal of Research in Marketing. 2003;20(1):31-43.

109. Ribbink D, Van Riel AC, Liljander V, Streukens S. Comfort your online customer: quality, trust and loyalty on the internet. Managing Service Quality: An International Journal. 2004.

110. Roostika R. The effect of perceived service quality and trust on loyalty: Customer's perspectives on mobile internet adoption. International Journal of Innovation, Management and Technology. 2011;2(4):286.

111. Chang C-S, Chen S-Y, Lan Y-T. Service quality, trust, and patient satisfaction in interpersonal-based medical service encounters. BMC health services research. 2013;13(1):22.

112. Ejiaku SA. Technology adoption: Issues and challenges in information technology adoption in emerging economies. Journal of International Technology and Information Management. 2014;23(2):5.

113. Sharma M, Sehrawat R. Quantifying SWOT analysis for cloud adoption using FAHP-DEMATEL approach: evidence from the manufacturing sector. Journal of Enterprise Information Management. 2020.

114. Dasgupta S, Agarwal D, loannidis A, Gopalakrishnan S. Determinants of information technology adoption: An extension of existing models to firms in a developing country. Journal of Global Information Management (JGIM). 1999;7(3):30-40.

115. Wang C, Teo TS, Liu L. Perceived value and continuance intention in mobile government service in China. Telematics and Informatics. 2020;48:101348.

116. Middleton B. Achieving US health information technology adoption: the need for a third hand. Health Affairs. 2005;24(5):1269-72.

117. Llewellyn S, Procter R, Harvey G, Maniatopoulos G, Boyd A. Facilitating technology adoption in the NHS: negotiating the organisational and policy context-a qualitative study. 2014.

118. Chen Y, Ding S, Zheng H, Zhang Y, Yang S. Exploring diffusion strategies for mHealth promotion using evolutionary game model. Applied Mathematics and Computation. 2018;336:148-61.

119. Lippert SK, Michael Swiercz P. Human resource information systems (HRIS) and technology trust. Journal of information science. 2005;31(5):340-53.

120. Lu J, Yu C-S, Liu C. Facilitating conditions, wireless trust and adoption intention. Journal of Computer Information Systems. 2005;46(1):17-24.

121. Beldad AD, Hegner SM. Expanding the technology acceptance model with the inclusion of trust, social influence, and health valuation to determine the predictors of German users' willingness to continue using a fitness app: A structural equation modeling approach. International Journal of Human-Computer Interaction. 2018;34(9):882-93.

122. Chang SE, Liu AY, Shen WC. User trust in social networking services: A comparison of Facebook and Linkedln. Computers in Human Behavior. 2017;69:207-17.

123. Fischer SH, David D, Crotty BH, Dierks M, Safran C. Acceptance and use of health information technology by community-dwelling elders. International journal of medical informatics. 2014;83(9):624-35.

124. Hair JF, Anderson RE, Tatham RL, William C. Black (1998), Multivariate data analysis: Upper Saddle River, NJ: Prentice Hall; 1998.

125. Ringle CM, Wende S, Will A. "SmartPLS 3." Boenningstedt: SmartPLS GmbH. Hamburg, Germany; 2015.

Page 20/28 
126. Gefen D, Straub DW, Boudreau M-C. Structural Equation Modeling and Regression: Guidelines for Research Practice. Communication of the Association for Information Systems. 2000;4:1 - 77.

127. Junglas I, Spitzmuller C, editors. Personality traits and privacy perceptions: an empirical study in the context of location-based services. Mobile Business, 2006 ICMB'06 International Conference on; 2006: IEEE.

128. Cook TD, Campbell DT, Day A. Quasi-experimentation: Design \& analysis issues for field settings. Boston, MA: Houghton Mifflin; 1979.

129. Wong KK-K. Partial Least Squares Structural Equation Modeling (PLS-SEM) Techniques Using SmartPLS. Marketing Bulletin. 2013;24:1-32.

130. Fornell C, Larcker DF. Evaluating structural equation models with unobservable variables and measurement error. Journal of Marketing Research. 1981;18(1):39 - 50.

131. Chin WW. Commentary: Issues and opinion on structural equation modeling. MIS Quarterly. 1998;22(1):vii - xvi.

132. Hair JF, Ringle CM, Sarstedt M. PLS-SEM: Indeed a silver bullet. Journal of Marketing theory and Practice. 2011;19(2):139-52.

133. Hu Lt, Bentler PM. Cutoff criteria for fit indexes in covariance structure analysis: Conventional criteria versus new alternatives. Structural equation modeling: a multidisciplinary journal. 1999;6(1):1-55.

134. Podsakoff PM, MacKenzie SB, Lee JY, Podsakoff NP. Common method biases in behavioral research: a critical review of the literature and recommended remedies. Journal of applied psychology. 2003;88(5):879.

135. Tamilmani K, Rana NP, Dwivedi YK. Consumer acceptance and use of information technology: A meta-analytic evaluation of UTAUT2. Information Systems Frontiers. 2020:1-19.

136. Moorthy K, Yee TT, T'ing LC, Kumaran VV. Habit and hedonic motivation are the strongest influences in mobile learning behaviours among higher education students in Malaysia. Australasian Journal of Educational Technology. 2019;35(4).

137. Hu PJ, Chau PY, Sheng ORL, Tam KY. Examining the Technology Acceptance Model Using Physician Acceptance of Telemedicine Technology. Journal of Management Information Systems. 1999;16(2):91 - 112.

138. Oliveira T, Thomas M, Baptista G, Campos F. Mobile payment: Understanding the determinants of customer adoption and intention to recommend the technology. Computers in Human Behavior. 2016;61:404-14.

139. Cao Y, Zhang J, Ma L, Qin X, Li J. Examining User's Initial Trust Building in Mobile Online Health Community Adopting. International Journal of Environmental Research and Public Health. 2020;17(11):3945.

140. Kundu S, Datta SK. Impact of trust on the relationship of e-service quality and customer satisfaction. EuroMed Journal of Business. 2015.

141. Lien C-h, Wu J-J, Chen Y-H, Wang C-J. Trust transfer and the effect of service quality on trust in the healthcare industry. Managing Service Quality. 2014.

142. Qalati SA, Vela EG, Li W, Dakhan SA, Hong Thuy TT, Merani SH. Effects of perceived service quality, website quality, and reputation on purchase intention: The mediating and moderating roles of trust and perceived risk in online shopping. Cogent Business \& Management. 2021;8(1):1869363.

143. Zhang L, Shang X, Sreedharan S, Yan X, Liu J, Keel S, et al. Predicting the development of type 2 diabetes in a large australian cohort using machine-learning techniques: longitudinal survey study. JMIR medical informatics. 2020;8(7):e16850.

144. Shin D-H. User experience in social commerce: in friends we trust. Behaviour \& information technology. 2013;32(1):52-67.

145. Li X, Hess TJ, Valacich JS. Using attitude and social influence to develop an extended trust model for information systems. ACM SIGMIS Database: the DATABASE for Advances in Information Systems. 2006;37(2-3):108-24.

146. Mansoor M. Citizens' trust in government as a function of good governance and government agency's provision of quality information on social media during COVID-19. Government Information Quarterly. 2021:101597.

147. Li W, Xue L. Analyzing the critical factors influencing post-use trust and its impact on citizens' continuous-use intention of e-government: Evidence from Chinese municipalities. Sustainability. 2021;13(14):7698.

148. Horst M, Kuttschreuter M, Gutteling JM. Perceived usefulness, personal experiences, risk perception and trust as determinants of adoption of egovernment services in The Netherlands. Computers in human behavior. 2007;23(4):1838-52.

149. Isa K, Palpanadan ST. Effect of Student Eating Habits and Implication towards their Health.

150. Uddin MT, Rasel MH, Dhar AR, Badiuzzaman M, Hoque MS. Factors determining consumer preferences for Pangas and Tilapia fish in Bangladesh: consumers' perception and consumption habit perspective. Journal of Aquatic Food Product Technology. 2019;28(4):438-49.

151. Sweeney F, Sharmin M, editors. Investigating Electronic Nicotine Delivery System Use Habits and Contexts: Habits, Locations, and Situations. 32nd Australian Conference on Human-Computer Interaction; 2020.

152. Guo X, Zhang X, Sun Y. The privacy-personalization paradox in mHealth services acceptance of different age groups. Electronic Commerce Research and Applications. 2016;16:55-65.

153. Limayem M, Hirt SG, Cheung CMK. How Habit Limits the Predictive Power of Intention: The Case of Information Systems Continuance. MIS Quarterly. 2007;31(4):705-37.

154. Sergueeva K, Shaw N, Lee SH. Understanding the barriers and factors associated with consumer adoption of wearable technology devices in managing personal health. Canadian Journal of Administrative Sciences/Revue Canadienne des Sciences de l'Administration. 2020;37(1):45-60.

Page $21 / 28$ 
155. Angst CM, Agarwal R. Adoption of Electronic Health Records in the Presence of Privacy Concerns: The Elaboration Likelihood Model and Individual Persuasion. MIS Quarterly. 2009;33(2):339 - 70.

156. Ray AW, Wong W, Newell S, Dillard J, editors. Beyond Privacy and Security: Ethical Dilemmas Resulting From Emergent Uses of Electronic Health Information. Seventh International Conference on Enterprise Systems, Accounting and Logistics (ICESAL); 2010 June 28 - 29; Rhodes Island, Greece.

157. Kiwanuka A. Acceptance process: The missing link between UTAUT and diffusion of innovation theory. American Journal of Information Systems. 2015;3(2):40-4.

158. Anderson CL, Agarwal R. The Digitization of Healthcare: Boundary Risks, Emotion, and Consumer Willingness to Disclose Personal Health Information. Information Systems Research. 2011;22(3):469 - 90.

159. Xiao N, Sharman R, Rao H, Upadhyaya S. Factors influencing online health information search: An empirical analysis of a national cancerrelated survey. Decision Support Systems. 2014;57:417 - 27.

160. Williams PA, Jenkins J, Valacich J, Byrd MD. Measuring Actual Behaviors in HCl Research-A call to Action and an Example. AIS Transactions on Human-Computer Interaction. 2017;9(4):339-52.

\section{Tables}

Table 1. Demographics of respondents

\begin{tabular}{|c|c|c|}
\hline Variable & Frequency & Percentage \\
\hline \multicolumn{3}{|l|}{ Gender } \\
\hline Male & 70 & $34.8 \%$ \\
\hline Female & 131 & $65.2 \%$ \\
\hline \multicolumn{3}{|l|}{ Age } \\
\hline 60 to 64 & 0 & $0.0 \%$ \\
\hline 65 to 69 & 91 & $45.3 \%$ \\
\hline 70 to 74 & 74 & $36.8 \%$ \\
\hline 75 to 79 & 18 & $9.0 \%$ \\
\hline 80 and above & 18 & $9.0 \%$ \\
\hline \multicolumn{3}{|l|}{ Educational Qualifications } \\
\hline None & 3 & $1.5 \%$ \\
\hline Primary & 40 & $19.9 \%$ \\
\hline Secondary & 38 & $18.9 \%$ \\
\hline Higher Secondary & 87 & $43.3 \%$ \\
\hline Bachelor's Degree & 24 & $11.9 \%$ \\
\hline Master's Degree & 6 & $3.0 \%$ \\
\hline Doctorate & 1 & $0.5 \%$ \\
\hline Others & 1 & $0.5 \%$ \\
\hline \multicolumn{3}{|l|}{ Marital Status } \\
\hline Single or never married & 32 & $15.9 \%$ \\
\hline Married or in a partnership & 137 & $68.2 \%$ \\
\hline Widowed & 24 & $11.9 \%$ \\
\hline Divorced or separated & 8 & $4.0 \%$ \\
\hline
\end{tabular}

Table 2. The Measurement Model 


\begin{tabular}{|c|c|c|c|c|c|c|c|}
\hline Constructs & Items & Loadings & Cronbach's alpha (a) & Rho_ & CR & AVE & VIF \\
\hline \multirow[t]{3}{*}{ Use Intention } & $\mathrm{Cl} 1$ & 0.955 & \multirow[t]{3}{*}{0.950} & \multirow[t]{3}{*}{0.951} & \multirow[t]{3}{*}{0.968} & \multirow[t]{3}{*}{0.910} & 5.499 \\
\hline & $\mathrm{Cl} 2$ & 0.961 & & & & & 5.969 \\
\hline & $\mathrm{Cl} 3$ & 0.945 & & & & & 4.305 \\
\hline \multirow[t]{6}{*}{ Performance Expectancy } & PE1 & 0.718 & \multirow[t]{6}{*}{0.896} & \multirow[t]{6}{*}{0.905} & \multirow[t]{6}{*}{0.920} & \multirow[t]{6}{*}{0.658} & 1.991 \\
\hline & PE2 & 0.833 & & & & & 2.687 \\
\hline & PE3 & 0.855 & & & & & 2.591 \\
\hline & PE4 & 0.861 & & & & & 2.711 \\
\hline & PE5 & 0.770 & & & & & 2.113 \\
\hline & PE6 & 0.821 & & & & & 2.347 \\
\hline \multirow[t]{4}{*}{ Effort Expectancy } & EE1 & 0.907 & \multirow[t]{4}{*}{0.911} & \multirow[t]{4}{*}{0.925} & \multirow[t]{4}{*}{0.937} & \multirow[t]{4}{*}{0.788} & 3.429 \\
\hline & EE2 & 0.871 & & & & & 2.244 \\
\hline & EE3 & 0.904 & & & & & 3.443 \\
\hline & EE4 & 0.867 & & & & & 2.788 \\
\hline \multirow[t]{4}{*}{ Facilitating Condition } & $\mathrm{FC} 1$ & 0.825 & \multirow[t]{4}{*}{0.842} & \multirow[t]{4}{*}{0.853} & \multirow[t]{4}{*}{0.895} & \multirow[t]{4}{*}{0.683} & 2.061 \\
\hline & $\mathrm{FC} 2$ & 0.875 & & & & & 2.758 \\
\hline & FC3 & 0.885 & & & & & 2.568 \\
\hline & FC4 & 0.707 & & & & & 1.498 \\
\hline \multirow[t]{4}{*}{ Social Influence } & SI1 & 0.885 & \multirow[t]{4}{*}{0.921} & \multirow[t]{4}{*}{0.922} & \multirow[t]{4}{*}{0.944} & \multirow[t]{4}{*}{0.810} & 3.220 \\
\hline & $\mathrm{SI} 2$ & 0.909 & & & & & 3.336 \\
\hline & SI3 & 0.940 & & & & & 4.917 \\
\hline & $\mathrm{SI} 4$ & 0.863 & & & & & 2.561 \\
\hline Habit & HA1 & 0.927 & 0.922 & 0.924 & 0.950 & 0.865 & 3.192 \\
\hline & HA2 & 0.921 & & & & & 3.333 \\
\hline & HA3 & 0.941 & & & & & 3.968 \\
\hline Hedonic Motivation & HM1 & 0.945 & 0.929 & 0.937 & 0.955 & 0.876 & 4.538 \\
\hline & $\mathrm{HM} 2$ & 0.958 & & & & & 5.410 \\
\hline & HM3 & 0.903 & & & & & 2.915 \\
\hline Price Value & PV1 & 0.878 & 0.902 & 0.909 & 0.939 & 0.837 & 2.328 \\
\hline & PV2 & 0.936 & & & & & 3.655 \\
\hline & PV3 & 0.929 & & & & & 3.361 \\
\hline Trust & TR1 & 0.899 & 0.935 & 0.938 & 0.953 & 0.836 & 3.188 \\
\hline & TR2 & 0.888 & & & & & 3.071 \\
\hline & TR3 & 0.945 & & & & & 6.375 \\
\hline & TR4 & 0.924 & & & & & 5.256 \\
\hline Service Quality & SQ1 & 0.823 & 0.939 & 0.949 & 0.952 & 0.768 & 2.544 \\
\hline & SQ2 & 0.879 & & & & & 3.500 \\
\hline & SQ3 & 0.916 & & & & & 4.538 \\
\hline & SQ4 & 0.866 & & & & & 3.020 \\
\hline & SQ5 & 0.899 & & & & & 3.752 \\
\hline & SQ6 & 0.872 & & & & & 3.148 \\
\hline
\end{tabular}




\begin{tabular}{|c|c|c|c|c|c|c|c|}
\hline \multirow[t]{4}{*}{ Government Policy } & GP1 & 0.925 & \multirow[t]{4}{*}{0.940} & \multirow[t]{4}{*}{0.941} & \multirow[t]{4}{*}{0.957} & \multirow[t]{4}{*}{0.848} & 4.500 \\
\hline & GP2 & 0.926 & & & & & 4.705 \\
\hline & GP3 & 0.925 & & & & & 4.165 \\
\hline & GP4 & 0.908 & & & & & 3.515 \\
\hline
\end{tabular}

Note: $C R=$ Composite Reliability; $A V E=$ Average Variance Extracted

Table 3. Fornetll-Larcker Criteria Analysis

\begin{tabular}{|c|c|c|c|c|c|c|c|c|c|c|c|}
\hline & $\mathrm{Cl}$ & $\mathrm{EE}$ & $\mathrm{FC}$ & GP & $\mathrm{HA}$ & $\mathrm{HM}$ & PE & PV & SQ & SI & $\mathrm{TR}$ \\
\hline $\mathrm{Cl}$ & 0.954 & & & & & & & & & & \\
\hline EE & 0.531 & 0.887 & & & & & & & & & \\
\hline FC & 0.545 & 0.616 & 0.826 & & & & & & & & \\
\hline GP & 0.453 & 0.308 & 0.288 & 0.921 & & & & & & & \\
\hline $\mathrm{HA}$ & 0.755 & 0.530 & 0.538 & 0.399 & 0.930 & & & & & & \\
\hline $\mathrm{HM}$ & 0.588 & 0.553 & 0.642 & 0.370 & 0.648 & 0.936 & & & & & \\
\hline PE & 0.547 & 0.574 & 0.452 & 0.535 & 0.539 & 0.527 & 0.811 & & & & \\
\hline PV & 0.549 & 0.422 & 0.406 & 0.502 & 0.595 & 0.482 & 0.499 & 0.915 & & & \\
\hline SQ & 0.658 & 0.428 & 0.560 & 0.527 & 0.629 & 0.624 & 0.468 & 0.588 & 0.876 & & \\
\hline SI & 0.558 & 0.503 & 0.477 & 0.498 & 0.549 & 0.628 & 0.552 & 0.577 & 0.590 & 0.900 & \\
\hline TR & 0.550 & 0.360 & 0.368 & 0.521 & 0.441 & 0.421 & 0.466 & 0.534 & 0.626 & 0.561 & 0.915 \\
\hline
\end{tabular}

Table 4. PLS-SEM Path Analysis Results Summary for Structural model 


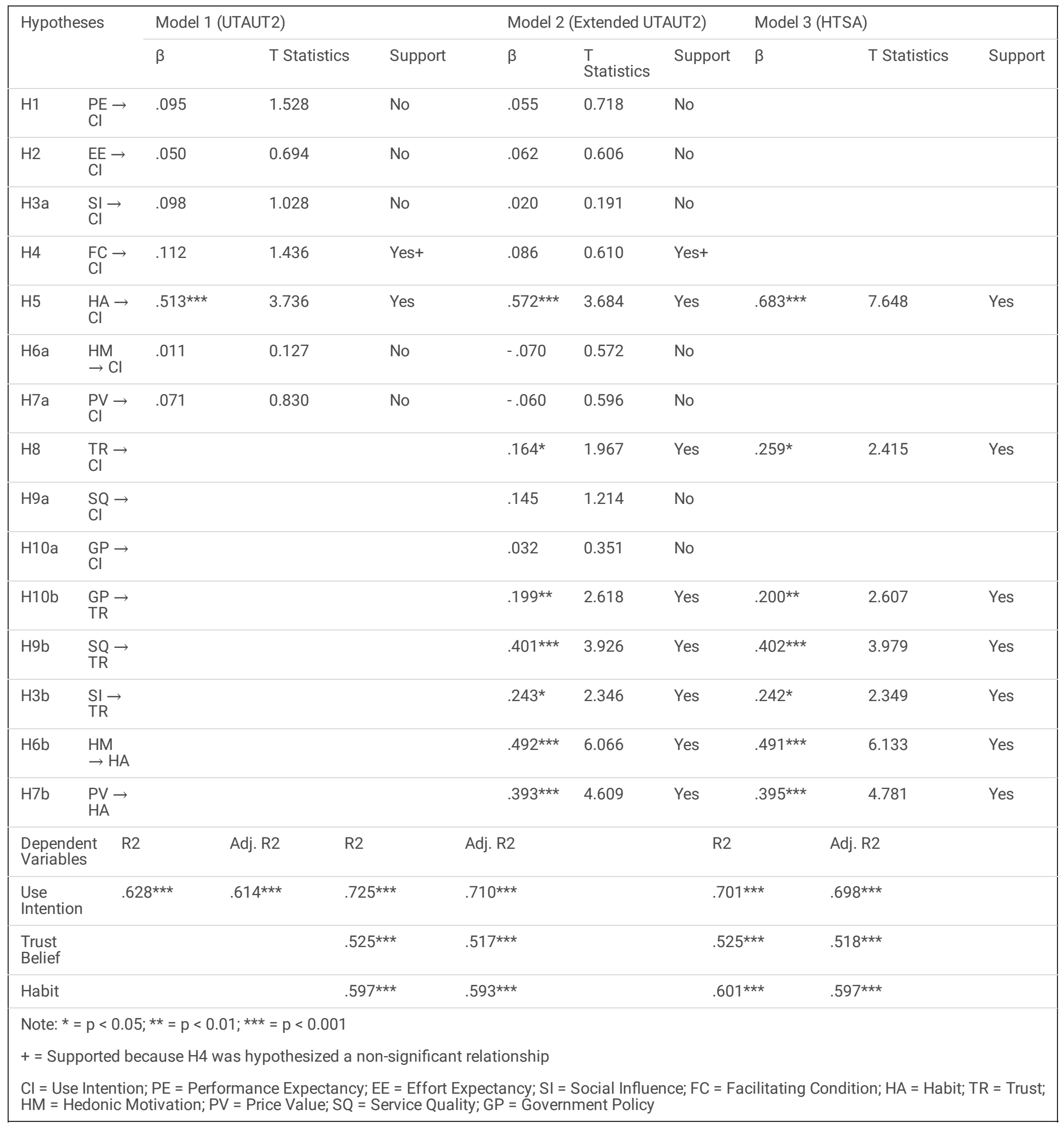

Table 5. Summary of the theoretical and practical implications 
Theoretical implications

The UTAUT model lacks several factors such as trust that influence the use indention and continuation of $\mathrm{mHealth}$, hence showing limitations in explaining technology adoption and use behavior.

HTSA model is more appropriate for explaining people's healthcare technology use intention behavior

UTAUT2 model is insufficient to provide a complete explanation of the voluntary use behavior of mHealth.

The applicability of the UTAUT2 model for understanding the use of technology is not well defined, specifically in the healthcare technology adoption domain.

UTAUT2 model does not take into consideration of cultural factors.
Practical implications

The policymakers need to increase the trust level of elderlies via social influence, service quality, and government policy.

The policymakers need to increase the habit of using mHealth services to enhance behavior intention.

The mhealth services providers need to increase the trust level of older people by showing their achievement, skills and reliability.

The mHealth services providers should apply data-mining techniques for improving service quality that can influence the trust level of elderlies.

Practitioners should implement planned and practical strategies to increase elderly users' level of trust.

\section{Figures}

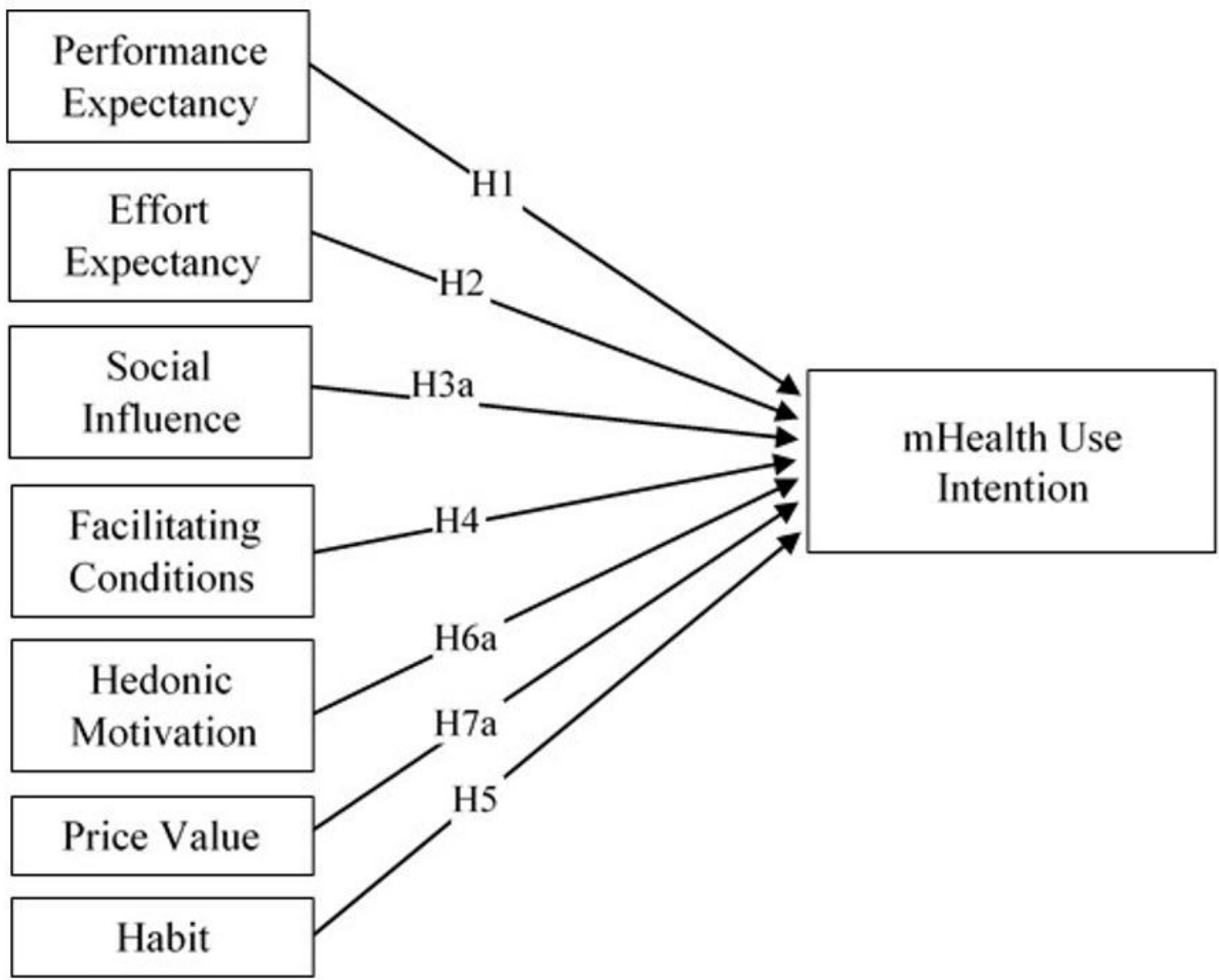

Figure 1

Research Model 1 - UTAUT2 (54) 


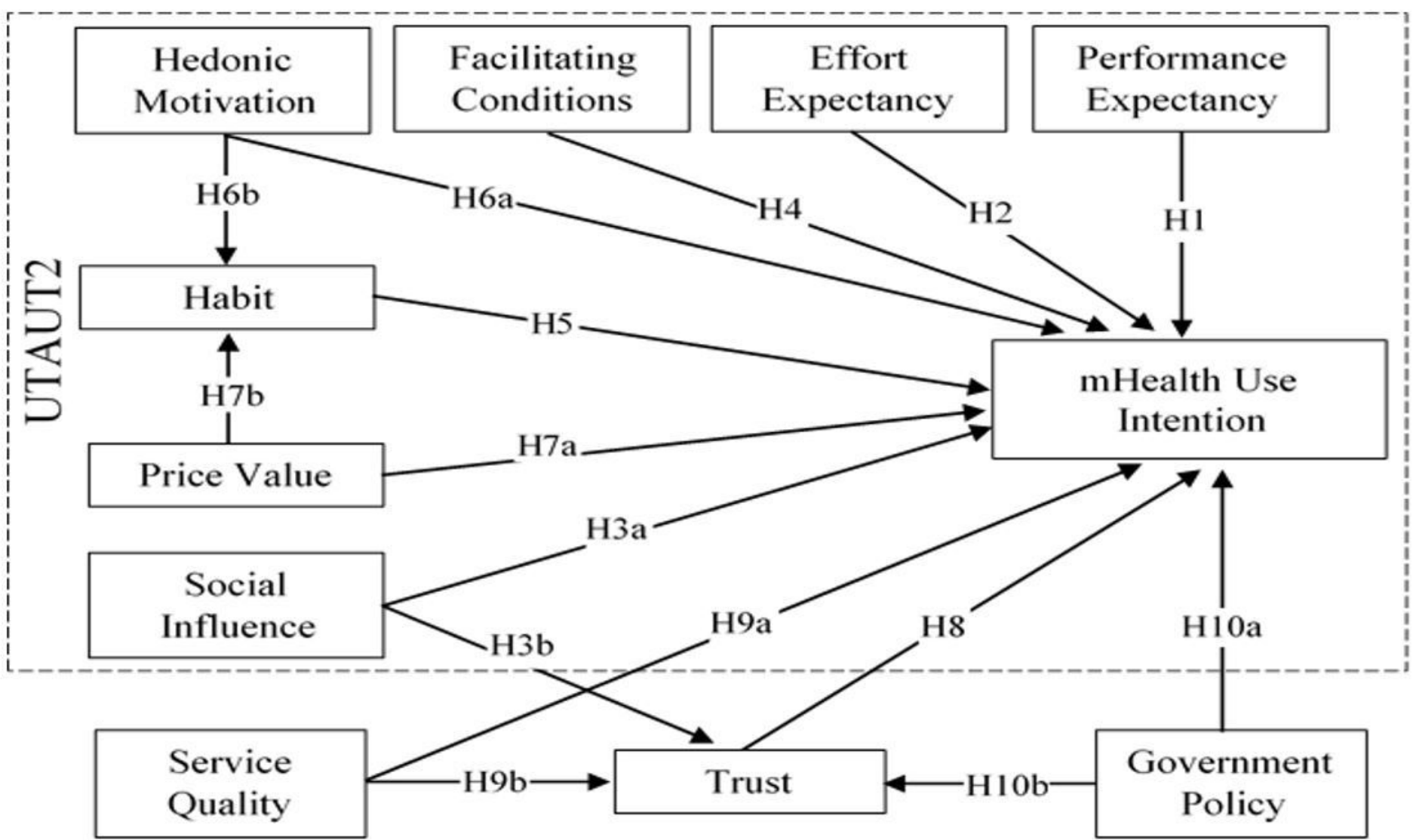

Figure 2

Research Model 2 - Extended UTAUT2 Model

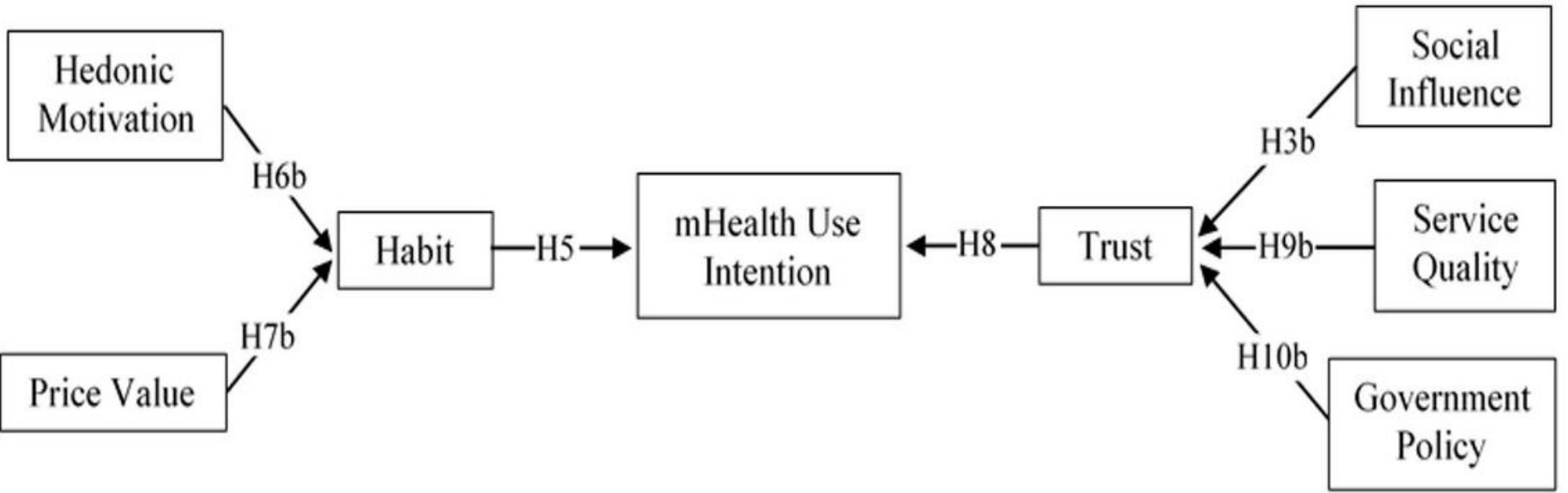

Figure 3

Research Model 3 - Health Technology Service Acceptance (HTSA) Model 


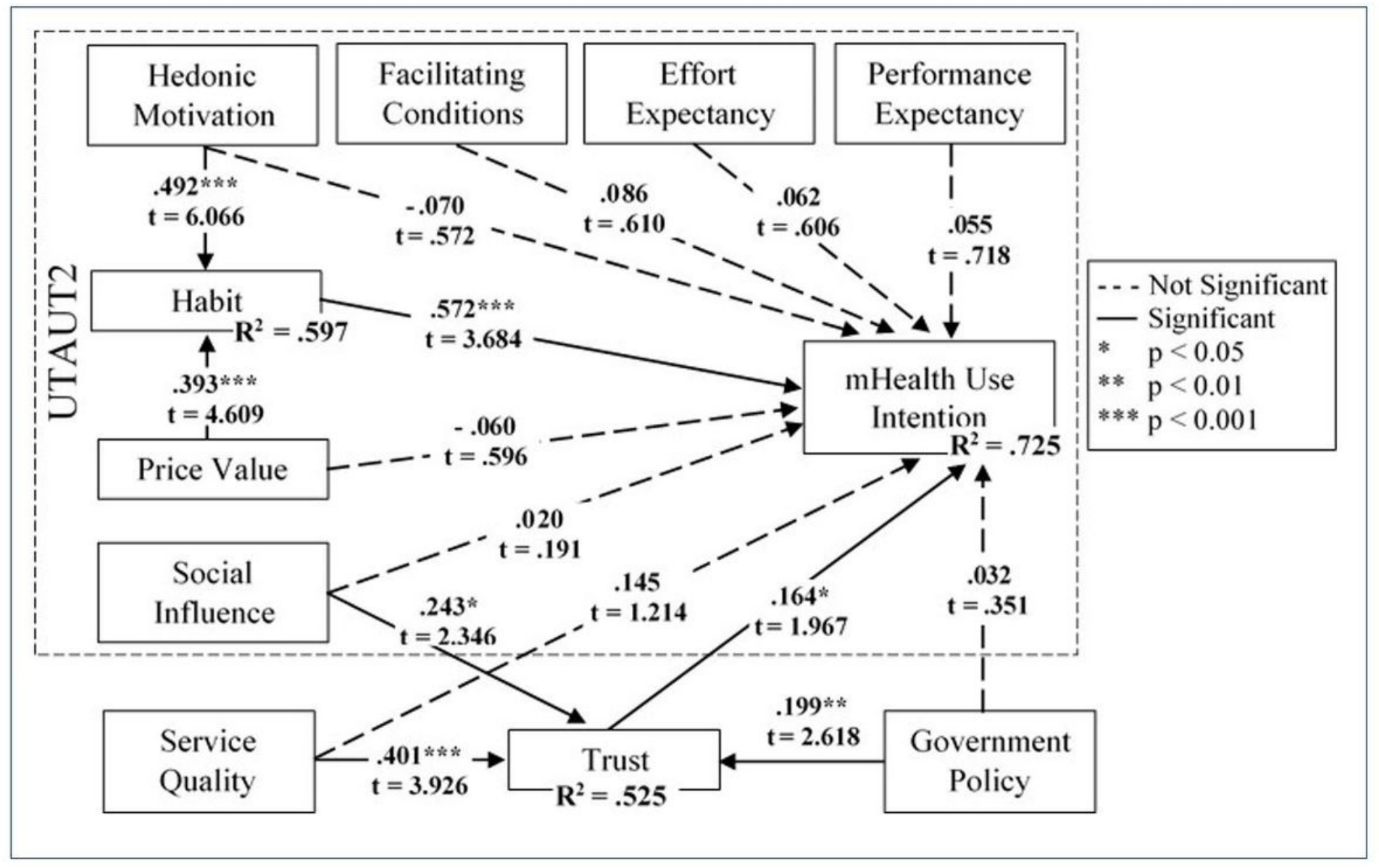

Figure 4

Path Significant Results for Extended UTAUT2 Model

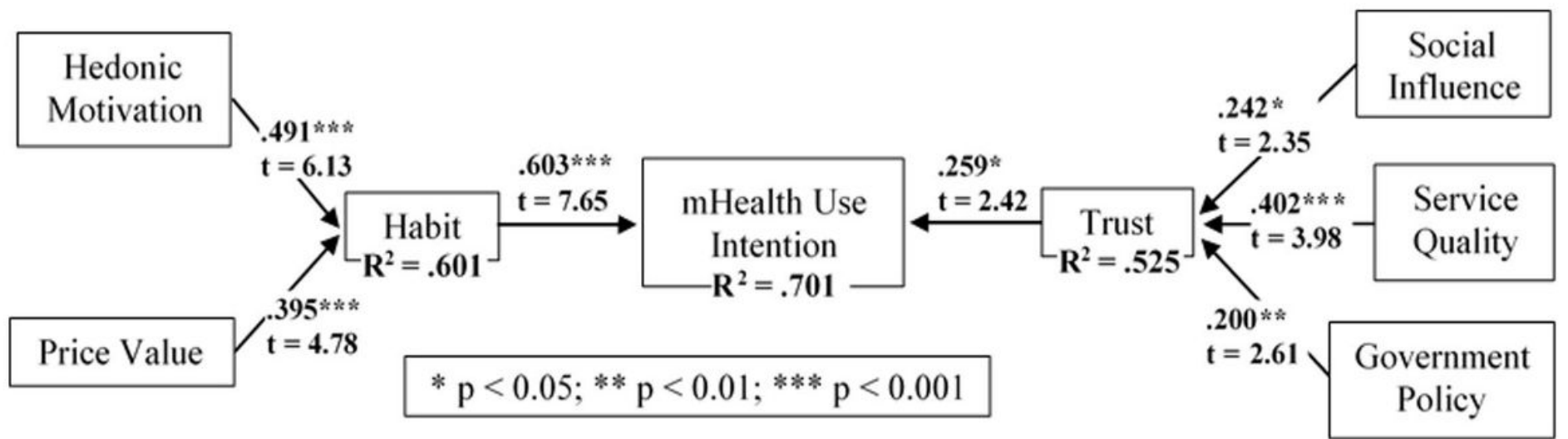

Figure 5

Path Significant Results for Simplified UTAUT2 - HTSA Model

\section{Supplementary Files}

This is a list of supplementary files associated with this preprint. Click to download.

- AppendixA.docx 